\title{
LA CONSTITUCIÓN Y LA TIRANÍA: EMILIO RABASA Y LA CARTA DE QUERÉTARO DE 1917
}

\author{
José Antonio Aguilar Rivera ${ }^{1}$ \\ Centro de Investigación y Docencia Económicas
}

El prestigio que alcanza un hombre no es la garantía de una nación; la paz que depende de una vida no es más que una tregua en el desorden.

Emilio Rabasa, La evolución histórica de México

\begin{abstract}
F milio Rabasa (1856-1930) fue un prominente abogado, Epolítico, novelista, diplomático, periodista e historiador. Perteneció a la élite política e intelectual del porfiriato.
\end{abstract}

Fecha de recepción: 18 de noviembre de 2015 Fecha de aceptación: 3 de enero de 2016

${ }^{1}$ El autor agradece a Tania Rabasa Kovacs (mi cómplice en el descubrimiento del estudio “fantasma”), Esteban González, Jaime del Arenal, José Montelongo, Michael O. Hyronimous, Eric Noé Jiménez Valerio, José Ramón Cossío, Jesús Silva Herzog-Márquez, Israel Arroyo, Paul Garner, Ignacio Marván, Aurora Cano Andaluz, Julio Manuel Martínez Rivas, Javier Garciadiego Dantán y Manuel Patiño por su ayuda, así como a dos revisores anónimos. Una parte de la investigación fue realizada gracias a una beca del Programa de Estancias Cortas de Investigación en la Colección Latinoamericana Nettie Lee Benson de la Universidad de Texas en Austin y la Secretaría de Relaciones Exteriores en 2015. 
Rabasa fue desde muy temprano miembro del grupo de los científicos, junto con otras personalidades como José Yves Limantour. Muy joven gobernó el estado de Chiapas (18911894). Rabasa también fue senador durante un largo periodo (que incluyó el comienzo de la revolución mexicana): de septiembre de 1894 a octubre de 1913. En esos 18 años Rabasa se convirtió en una figura importante en el escenario nacional. Su reputación creció como una autoridad en temas de derecho constitucional. Rabasa logró ese prestigio por medio de su cátedra en la Escuela Nacional de Jurisprudencia, pero sobre todo gracias a la publicación de dos libros centrales para la historia del constitucionalismo mexicano: $E l$ artículo 14 (1906) y La Constitución y la dictadura (1912). En este último libro Rabasa reconoció que el gobierno de Díaz había sido una dictadura impuesta por la inaplicabilidad de la Constitución liberal de 1857. Los defectos de diseño institucional de esa carta la hacían impracticable. Benito Juárez aprendió muy pronto la lección. "La Constitución", afirmaba Rabasa, "que para Juárez no podía ser más que título de legitimidad para fundar su mando, y bandera para reunir parciales y guiar huestes, era inútil para todo lo demás. La invocaba como principio, la presentaba como objeto de la lucha; pero no la obedecía, ni podía obedecerla y salvarla a la vez". Rabasa le criticó a la Constitución de 1857 el desequilibrio entre el Poder Ejecutivo y el Legislativo. Los constituyentes habían creado un presidente estructuralmente débil frente al Congreso.

Cuando Porfirio Díaz renunció en 1911 Rabasa estaba en el Senado. Ahí fue parte de una corriente reformista que pugnó por modificar las leyes electorales. En 1912 fue la figura central en la creación de la Escuela Libre de Derecho. 
El surgimiento de esta institución se debió a la intromisión del gobierno de Madero en la Escuela Nacional de Jurisprudencia. Como senador, Rabasa apoyó en 1913 el golpe de Victoriano Huerta contra el gobierno de Francisco I. Madero. Huerta intentó, sin éxito, nombrar a Rabasa embajador en Estados Unidos y rector de la Universidad Nacional. Finalmente, cuando se desató el conflicto con Estados Unidos, producto de la intervención estadounidense en Veracruz en abril de 1914, Huerta nombró a Rabasa cabeza de la delegación mexicana a la conferencia de intermediación que se celebró ese año en Niagara Falls, Canadá. Al poco tiempo de concluidas las infructuosas negociaciones, Huerta dimitió y Rabasa se encontró en el exilio en Nueva York. Ahí permaneció hasta que el gobierno revolucionario lo dejó retornar a México en 1920.

Además de sus actividades políticas, Rabasa era un abogado respetado. Al igual que otras figuras públicas, como Joaquín Casasús y Francisco León de la Barra, el despacho legal de Rabasa representó a poderosos petroleros extranjeros, como Edgard Doheny y Weetman Pearson. De ahí que Rabasa tuviera relación con los intereses petroleros en México.

En el otoño de 1916 Emilio Rabasa, jurista, hombre de Estado y negociador internacional fallido, miraba desde su exilio en Nueva York con mucho escepticismo los acontecimientos de su patria. En particular, mostraba suspicacia por el proyecto de constitución que Venustiano Carranza, Primer Jefe del Ejército Constitucionalista, había propuesto al Congreso que se reuniría en Querétaro. A José Yves Limantour, quien se encontraba en París, le escribió el 19 de noviembre, un día antes de que se cumpliera la efeméride revolucionaria: 
Ni a Santa Anna [se] le ocurrió dar un proyecto de constitución hecho y derecho a los constituyentes como lo hace ahora el Primer Jefe. Supongo que es obra de Macías y Luis Manuel Rojas no sin ideas del mismo Carranza que, como Napoleón, es capaz de legislar en las materias más arduas en los descansos que las armas le permiten. Tengo la más viva curiosidad de conocer nuestra nueva ley fundamental; pero creo que será secreta hasta que esté firmada por los nuevos Arriagas y Matas [que] van a inmortalizarse en Querétaro. ${ }^{2}$

Cuatro meses después se satisfizo la curiosidad de Rabasa. El 12 de marzo de 1917, menos de un mes después de que se promulgara en Querétaro la nueva carta magna, Rabasa le escribió a Limantour:

[...] yo también quisiera hablarle a usted de nuestra nueva constitución, pero en realidad gastaríamos usted y yo inútilmente párrafos que podemos dedicar a puntos de mayor

${ }^{2}$ Emilio Rabasa a José Yves Limantour, Nueva York, 19 de noviembre de 1916. CEHMC, AJYL, CDLIV.2a. 1910.24.215. Rabasa se refería a José Natividad Macías y a Luis Manuel Rojas. De acuerdo con Marván, “el primero abogado exitoso, con larga trayectoria legislativa y docente, tenía 59 años y era rector de la Universidad Nacional al momento de postularse al Congreso Constituyente; y el segundo, jalisciense, antireyista, posteriormente maderista, diputado en la XXVI Legislatura, encarcelado por Huerta en octubre de 1913, después incorporado al constitucionalismo y ya tenía 45 años cumplidos cuando fue constituyente. Ambos fueron el núcleo fundamental de la Sección de Legislación Social de la Secretaría de Instrucción Pública, fundada por el Primer Jefe para preparar la redacción de los decretos revolucionarios que siguieron a las adiciones del Plan de Guadalupe, firmadas y publicadas el 12 de diciembre de 1914 y fue precisamente a ambos a quienes en febrero de 1916 Carranza les encargó formalmente el Proyecto de Reformas a la Constitución que sería presentado al Constituyente". Marván, "Los constituyentes abogados", p. 5. 
importancia en nuestras cartas, puesto que en todo lo relativo a la nueva ley es seguro que estamos sobradamente de acuerdo. Yo sólo diré a usted un concepto general: no es posible que subsista como ley fundamental de un país lo que establece como base de organización el desconocimiento de los derechos más elementales y la imposición legal de la tiranía. ${ }^{3}$

El rechazo de Rabasa involucraba una paradoja: por un lado, muchos le atribuyeron la inspiración de la nueva carta mientras que él la rechazó tajantemente en un inicio. Se ha estudiado con bastante detalle la influencia del pensamiento de Rabasa en la Constitución de 1917.4 Para algunos críticos Rabasa fue un legislador "no reconocido”, como diría Shelley. Lo que no se ha hecho es ofrecer un análisis de las opiniones del propio Rabasa sobre el producto Constitucional del nuevo Leviatán revolucionario. ¿Qué pensaba Emilio Rabasa de la Constitución de 1917? Responder esta pregunta no es sencillo. En los 13 años que Rabasa vivió después de promulgada la Constitución de Querétaro escribió muy poco sobre ella. Volvió del exilio en 1920 y entonces evitó, debido a su pasado político, pronunciarse sobre la ley fundamental de los revolucionarios. La prudencia política prevaleció. Con todo, debería sorprendernos la poca atención que han recibido las opiniones de Rabasa sobre la Constitución actual. Parecería como si el autor de La Constitución y

3 Rabasa a Limantour, 12 de marzo de 1917, CEHMC, AJYL, CDLIV.2a. 1910.24.221.

4 Los conocidos textos de Manuel Herrera y Lasso, Alfonso Noriega, Antonio Martínez Báez y Jorge Gaxiola sobre la influencia de Rabasa en la Constitución de 1917 están recogidos en la antología de Andrés Serra Rojas. Véase SErra, Antología, pp. 61-120. Para un análisis de la influencia véase Hale, Emilio Rabasa, pp. 133-139. 
la dictadura nunca hubiera visto la nueva carta que se promulgó en Querétaro.

Para reconstruir la posición de Rabasa sobre la Constitución de 1917 es necesario echar mano de materiales dispersos y fragmentarios (muchos de ellos no públicos): sus clases como profesor de derecho constitucional, su correspondencia y algunos cuantos artículos de prensa. Pero, sobre todo, de un texto inédito y recientemente descubierto: el estudio legal que Rabasa elaboró en abril de 1917 sobre el artículo 27 constitucional y que hasta ahora había estado perdido.

\section{EL ESTUDIO “FANTASMA”}

En 1956 Hilario Medina, exdiputado constituyente de Querétaro y posteriormente ministro de la Suprema Corte, analizó la influencia del pensamiento de Rabasa en la carta de 1917. ${ }^{5}$ Ahí identificó correctamente la tensión ideológica que existía entre la obra de esa asamblea y las ideas del jurista. "Hay una parte de la Constitución vigente", afirmaba Medina, "la del Derecho Social, que nada debe a Rabasa, sencillamente porque éste la ignoró, nunca la entendió, nunca quiso explicarla ni comentarla. Su silencio era una franca hostilidad". 6

La renuencia de Rabasa a pronunciarse públicamente sobre la obra del Constituyente de Querétaro era comprensible. Sabía lo que se había dicho de él en los debates del Congreso. En la sesión del 20 de enero de 1917, en la que

${ }^{5}$ Medina fue miembro de una de las dos comisiones de Constitución del Congreso Constituyente que se formaron para dictaminar el proyecto. Tenía en ese entonces 25 años.

${ }^{6}$ Medina, "Emilio Rabasa y la Constitución de 1917”, p. 180. 
se discutió la estructura del poder judicial, el diputado José María Truchuelo se expresó de esta manera sobre el dictamen de los artículos 94 al 102 del proyecto de constitución:

[...] no me explico, repito, cómo la Comisión nos quiere hacer retroceder siglos y siglos para venir a sostener como principios de ese dictamen teorías que han sido ya cubiertas con el polvo del olvido y del desprecio jurídico. Si examinamos cuáles pueden haber sido esos motivos, no encuentro otros, señores, sino la lectura de un libro reaccionario en muchos puntos: $L a$ Constitución y la dictadura de Emilio Rabasa. No necesito discutir aquí la personalidad de un hombre que con todo gusto voló hacia la Casa Blanca a representar al usurpador Huerta. (Voces: ¡Muy bien dicho está eso!) Simple y sencillamente, señores, el anhelo, el entusiasmo con que ese hombre fue a cumplir los deseos de un usurpador, nos dicen que sus obras tienen que responder a sus aspiraciones, a sus principios y a todas aquellas tendencias que nos han revelado por sus funciones políticas. Ahora don Emilio Rabasa es el que viene sentando la absurda idea de que el poder judicial no es poder, es un departamento judicial. ${ }^{7}$

No existe en los años posteriores a la promulgación de la Constitución de 1917 un análisis sistemático de ella por parte de Rabasa. En los pocos aspectos en los que discutió la obra del constituyente de Querétaro lo hizo para referirse a aspectos formales (como la inamovilidad de los ministros de la Suprema Corte) y evadió la discusión ideológica de la Constitución. Sin embargo, hay una notable excepción: al poco tiempo de que entrara en vigor la carta magna, el

${ }^{7}$ Marván, Nueva edición del Diario de Debates, p. 2044. 
inglés Weetman Pearson (Lord Cowdray), ingeniero y uno de los contratistas petroleros más importantes del mundo, le comisionó a Rabasa, a la sazón exiliado en Nueva York, un estudio legal del artículo 27. ${ }^{8}$ Herbert Carr, agente de Pearson, le solicitó el análisis del artículo para entender cómo la nueva constitución podría afectar los intereses económicos de Pearson en México. ${ }^{9}$

El 12 de abril de 1917 Rabasa le escribió a Limantour desde Nueva York: "la Casa que usted debe suponer me encargó un estudio legal completo del famoso artículo 27 recomendándome lo terminara cuanto antes y este encargo me tuvo enteramente ocupado durante dos semanas. Hace cuatro días lo entregué a la Casa de aquí para ser enviado a México" ${ }^{10}$ Según Hale, el trabajo, traducido por su hijo Óscar, "apareció anónimamente en inglés (no se conoce el título) y también fue enviado a México para ser publicado". ${ }^{11}$ Hasta ahora, el "estudio fantasma”, como lo bautizó Hale, no había sido hallado. Aunque Hale afirma que el documento fue publicado, no cita la fuente y no hay rastros de él ni en México ni en ningún otro lugar.

Cabe mencionar que Pearson también subvencionó por los mismos años a Rabasa para que escribiera La evolución histórica de México. ${ }^{12}$ El propósito original era traducir

\footnotetext{
${ }^{8}$ Hale, Emilio Rabasa, p. 128.

${ }^{9}$ Sobre las actividades de las empresas de Pearson en México véase GARNER, British Lions and Mexican Eagles.

${ }^{10}$ Rabasa a Limantour, 12 de abril de 1917, CEHMC, AJYL, CDLIV.2a. 1910.24.223.

11 Hale, Emilio Rabasa, p. 129.

12 Pearson le pagó a Rabasa 2500 dólares para subvencionar la escritura de La evolución histórica de México. El libro estaría dirigido al público
} 
ambos textos y publicarlos anónimamente. Se sabe que además de la copia del estudio que el autor le entregó a Carr, existió por lo menos otra que Rabasa le remitió a Limantour a Francia. La copia de Pearson no ha sido hallada en los archivos. ${ }^{13}$ Los supuestos envíos a México no están documentados. El 6 de septiembre de 1917 Limantour le escribió a Rabasa desde Biarritz: "el otro trabajo, el del Art. 27 de la nueva constitución, sí me ha llegado, y lo he leído con verdadero deleite" ${ }^{14}$ Sin embargo, por razones que se ignoran, el estudio referido tampoco se encuentra en el archivo de Limantour. Según Hale, la correspondencia de Rabasa no revelaba nada específico sobre el contenido del estudio, a excepción de la afirmación general, que ya hemos citado, de que la Constitución implicaba "el desconocimiento de los derechos más elementales y la imposición legal de la tiranía”.

Probablemente una de las raíces antiliberales más importantes del constitucionalismo de Querétaro se encuentre en su tratamiento de la cuestión agraria. Hale creía que se podían encontrar algunas pistas del tenor del "estudio fantasma" en una breve discusión durante el curso que Rabasa dictó en la Escuela Libre de Derecho en 1928. ${ }^{15}$ Ahí afirmó que "el

lector de Estados Unidos, Europa y América Latina. Hale, Emilio Rabasa, p. 90.

13 El estudio, de acuerdo con Paul Garner, no obra en los archivos de la British Petroleum. Garner buscó el texto a petición de Hale hace varios años. En el archivo está, sin embargo, correspondencia de John Body, mano derecha de Pearson en México, en la cual menciona la idea de comisionar el estudio a Rabasa. Paul Garner, comunicación personal, 7 de septiembre de 2014.

${ }^{14}$ José Yves Limantour a Emilio Rabasa, Biarritz, 6 de septiembre de 1917. CEHMC, AJYL, CDLIV.2a. 1910.24.231.

${ }^{15}$ Hale, Emilio Rabasa, p. 129. 
artículo no es artículo; es un tratado de la propiedad; no tiene forma legal”. ${ }^{16}$ Esta era una expresión más bien enigmática.

El estudio ha sido encontrado, pero antes de analizarlo vale la pena explicar el hallazgo en detalle. Lo que no se sabía hasta ahora era que Rabasa en algún momento le envió el análisis a un tercer destinatario: William F. Buckley (18811958). Buckley era un texano amigo cercano y socio de Emilio Rabasa. Era un abogado que en 1908 viajó a México para estudiar derecho en la Escuela Nacional de Jurisprudencia. Al término de sus estudios trabajó en un despacho de abogados. En 1912 abrió su propio bufete, junto con dos de sus hermanos en Tampico, pues la industria petrolera hacía atractiva la profesión legal en esa región. De esa época datan las relaciones entre Buckley y Rabasa. En 1914 Rabasa era el abogado de Buckley en la Ciudad de México. Ese mismo año el texano decidió dejarles el despacho a sus hermanos $y$ entrar directamente en el negocio petrolero, para lo cual adquirió propiedades en México. En el contexto del conflicto entre las compañías petroleras y el gobierno mexicano Buckley fue un partidario abierto de la intervención. Para instigarla formó una organización de afectados en Estados Unidos y atestiguó en las audiencias del Senado estadounidense presididas por el senador Albert Fall celebradas en 1919. Álvaro Obregón lo expulsó del país en 1921.

Aunque Buckley y Rabasa sostuvieron una larga relación de amistad y negocios, Hale documenta una pausa de cuatro años (1915-1919) en su correspondencia. ${ }^{17} \mathrm{El} 20$ de septiembre de 1919 un P. N. Goodman, posiblemente socio de

\footnotetext{
${ }^{16}$ Rabasa, "Curso de derecho", p. 607.

17 Hale, Emilio Rabasa, p. 109.
} 
Buckley, le escribió al texano una carta que parecería ser la respuesta a una petición de información respecto a la existencia de opiniones críticas de mexicanos de la Constitución de 1917. Es conveniente citar la misiva en extenso. Goodman le decía a Buckley:

Le he pedido a la Revista Mexicana que me mande una colección de los artículos recientemente publicados del Sr. Jorge Vera Estañol relacionados con la Constitución de Querétaro promulgada por el Congreso en 1917 y, especialmente, con el artículo 27 de ese instrumento. El trabajo más valioso en conexión con el artículo 27 es una monografía escrita por nuestro amigo Mr. Rabith a finales de 1916 a petición de cierto interés petrolero. Sé que Mr. Rabith le envió una copia, la cual usted le devolvió a través de Mr. Iturbide en Laredo, Texas, pero él nunca la recibió. Mr. Rabith le envió la única copia que tenía.

Me complace enviarle un panfleto que tengo, el cual contiene la crítica más firme y erudita del mentado artículo 27 . Es el informe de cierto comité del "Primer Congreso Nacional de Industriales" reunido en la Ciudad de México a finales de 1917. Los miembros del comité son, como usted verá, Francisco Viesca Lobatón, Manuel Castelazo Fuentes, Rafael Pardo, José Lorenzo Cosío, Eduardo García y Adolfo Martínez. El único y exclusivo autor del informe es el Lic. Viesca Lobatón, un hombre muy docto y honesto, que fuera secretario privado de Rafael Hernández, ministro de Fomento en el régimen de Madero. Después del trabajo de Mr. Rabith, el cual no creo esté disponible, el informe del Sr. Viesca Lobatón es un estudio encomiable del artículo 27 de la Constitución de Querétaro. Se lo mandé separadamente. ${ }^{18}$

${ }_{18}$ P. N. Goodman a William Buckely Sr., Nueva York, 20 de septiembre de 1919, 153.3, William F. Buckley Sr. Papers, Benson Latin American 
Es evidente que "Mr. Rabith" era el nombre en clave de Emilio Rabasa, quien debía tener cierta relación ("nuestro amigo") con Goodman. ${ }^{19}$ La carta revela que la posición de Rabasa era compartida por otros exiliados desafectos a la Revolución: como Jorge Vera Estañol, Nemesio García Naranjo y Toribio Esquivel Obregón. Varios prominentes exiliados criticaron ácidamente la nueva constitución cuando ésta se promulgó. Por ejemplo, en 1919, la Revista Mexicana, el semanario que García Naranjo publicaba en San Antonio, Texas, publicó una serie de 13 artículos críticos de la Constitución de Querétaro escritos por Vera Estañol. Para el antiguo profesor de derecho esa carta era en realidad bolchevismo. Sin embargo, entre las voces disidentes, la de Rabasa era sin duda la más autorizada.

En el legajo del archivo, inmediatamente después de la carta arriba transcrita, se encuentra un manuscrito mecanografiado de 60 páginas, sin firmar, titulado "El derecho de propiedad y la Constitución mexicana de 1917”. Parecería, por el orden secuencial de los documentos, que el manuscrito es el panfleto de Viesca Lobatón referido en la carta de Goodman. Sin embargo, no es así. Al cotejar ambos documentos se advierte de inmediato que son completamente distintos. Es probable que otros investigadores hayan sido despistados por la mención del panfleto de Viesca Lobatón en la carta de Goodman que antecede al estudio.

Collection, University of Texas Libraries, The University of Texas Libraries, The University of Texas at Austin. BLAC, WBP. Traducción del autor.

${ }^{19}$ Sin embargo, Goodman se equivocaba al datar la elaboración del estudio sobre el artículo 27 en 1916. 
En efecto, en 1917 se publicó un pequeño libro: El artículo 27 constitucional (Constitución de 1917). Dictamen de la Comisión nombrada por el Primer Congreso Nacional de Industriales. El panfleto de Viesca Lobatón, impreso en México, tiene 123 páginas y está firmado por las seis personas mencionadas en la carta de Goodman a Buckley. Los autores concluían que había una imperiosa necesidad "de que se modifique el contenido del Artículo 27 Constitucional, de acuerdo con los intereses morales, materiales, económicos y sociales que representan las industrias del país". ${ }^{20}$

Tras un análisis textual y sustantivo del documento hallado en al archivo de Buckley es posible concluir que El derecho de propiedad y la Constitución mexicana de 1917 es el estudio perdido de Rabasa sobre el Artículo 27. ${ }^{21}$ Podemos conjeturar sobre lo ocurrido. Goodman creía que Buckley no tenía el estudio de Rabasa. Sin embargo, esto no era así. Es claro que, a pesar de la pausa en su correspondencia, en algún momento entre 1917 y 1919 Rabasa le remitió a Buckley el documento sobre el artículo 27, probablemente para recibir comentarios. La copia que existe en el archivo es un borrador, pues tiene anotaciones y correcciones manuscritas del autor. Según Goodman, Buckley afirmó haberle regresado el documento a Rabasa por medio de un tercero, pero aparentemente no fue así. Probablemente, el texano conservó el escrito de Rabasa sin que éste lo supiera. ${ }^{22}$ Tiempo después,

20 Viesca Lobatón, El artículo 27 constitucional, p. 123.

21 El derecho de propiedad y la Constitución mexicana de 1917. BLAC, WBP, 153.3, 124. Se prepara una edición del estudio que aparecerá en breve. 22 Probablemente Buckley conservó el documento para emplear sus argumentos en la comparecencia que tuvo ante un subcomité del Senado estadounidense en 1919 respecto al tema de las reclamaciones de ciu- 
Buckley recibió la carta de Goodman que archivó junto con el estudio de Rabasa, por estar ambos documentos relacionados. Ignoramos si Buckley recibió o no el panfleto de Viesca Lobatón mencionado en la misiva, pero este documento no se encuentra en el archivo. Su ausencia ayuda a explicar por qué no se identificó antes el estudio de Rabasa.

¿Por qué no mencionó Rabasa el artículo 27 - ni la crítica contenida en el estudio - en su Evolución histórica de México, en el apartado de "El problema de las tierras" ?23 Era de esperarse alguna mención, sobre todo cuando escribió ambos textos al mismo tiempo. Me parece que por dos razones que se explican, a su vez, por la azarosa historia de ese libro. En primer lugar, porque desde 1916 - cuando empezó a trabajar en La evolución - Rabasa deseaba explícitamente evitar la confrontación abierta con la Revolución. Ese año le dijo a Limantour que su libro no "estaría dirigido contra la revolución y que se referiría a ella de manera precisa, breve y clara". ${ }^{24}$ No quería que ese libro fuera leído como parte de una campaña política o como una obra que combatiera abiertamente a la Revolución..$^{25}$ El libro, como se ha dicho, estaba concebido originalmente para ser traducido y publicado de manera anónima. Sin embargo, Rabasa creía que el autor sería reconocido y el gobierno de Carranza tomaría represalias en su contra. Limantour coincidía:

dadanos estadounidenses en México. En efecto, como señala Hale, en esa audiencia Buckley condenó el concepto del artículo 27 de la propiedad como una "función social” y "comparó el México de Carranza con la Rusia de Trotsky”. Hale, Emilio Rabasa, pp. 109-110.

${ }^{23}$ Rabasa, La evolución histórica de México, pp. 226-250. Le agradezco a Jaime del Arenal que formulara esta pregunta.

${ }^{24}$ Hale, Emilio Rabasa, p. 89.

${ }^{25}$ Hale, Emilio Rabasa, p. 90. 
creía que "sería imposible impedir que nuestros perseguidores descubran quiénes son los verdaderos autores y sus simpatizantes”. Era, afirmó Rabasa, “cosa de sumar dos y dos" ${ }^{26}$ Por eso se demoró su publicación. ${ }^{27}$

En septiembre de 1917 Limantour le escribió a Rabasa que tenía problemas para comunicarse con Pearson debido a los retrasos en las comunicaciones por la guerra. La traducción se complicó y al final no se materializó. Las mismas razones que llevaron a que La evolución no se publicara anónimamente probablemente expliquen también por qué al final no se publicó el estudio del artículo 27, en inglés o español: dificultades logísticas de Pearson y el temor de Rabasa a ser descubierto, a pesar del anonimato. Las intenciones, manifiestas en la correspondencia, de publicar el estudio, se quedaron en eso.

Finalmente, en 1918 Rabasa decidió publicar La evolución histórica en castellano, usando su nombre. Para poder firmarlo y no exponerse políticamente de manera innecesaria eliminó capítulos dedicados a la Revolución, mientras que expandió otras partes del libro. ${ }^{28}$ Es plausible pensar que lo que pudiera haber dicho a manera de crítica del artículo 27 fue eliminado en ese corte de 1918. Poco antes de la publicación del libro, en 1920, Rabasa repetiría que su deseo era mantener la serenidad, evitar el combate y apegarse a su principal objetivo: "defender el antiguo régimen, que es la mejor defensa de la nación”. ${ }^{29}$ Las referencias al estudio sobre el artículo 27 estaban claramente fuera de lugar en

26 Hale, Emilio Rabasa, p. 91.
27 Hale, Emilio Rabasa, p. 91.
28 Hale, Emilio Rabasa, p. 91.
29 Hale, Emilio Rabasa, p. 91. 
un libro que deseaba evitar el conflicto abierto. Finalmente, para cuando Rabasa mandó a la imprenta La evolución histórica de México, ya era clara su intención de regresar del exilio, y por ello no deseaba antagonizar al nuevo régimen. Eso también explicaría por qué Rabasa no "reconstruyó” el estudio sobre la propiedad a su regreso a México. ${ }^{30}$

Por el contenido del estudio legal era claro que Rabasa no podría firmarlo con su nombre; tampoco era modificable, como sí lo fue La evolución. El estudio hubiera sido leído como un ataque frontal de Rabasa a la obra constitucional de la Revolución. La publicación anónima era, por otro lado, demasiado riesgosa para el autor. Puede inferirse de la carta de Goodman a Buckley que en 1919 el estudio de Rabasa no había sido publicado de ninguna forma y por eso no estaba "disponible". ${ }^{31}$

HELLO MR. RABITH

La importancia del estudio legal del artículo 27 es evidente. Se trata del único escrito largo y sustancioso de Emilio Rabasa en el cual critica abiertamente y por razones ideológicas

30 Ya en febrero de 1919 Rabasa consideraba seriamente volver a México, pues un pariente le había informado que el gobierno le regresaría sus propiedades y aseguraba que a su regreso encontraría "absoluta libertad”. Hale, Emilio Rabasa, p. 113. A Buckley le escribió: "a pesar de que la gente sabe que estoy contra Carranza, tienen que admitir que acepto la victoria de los revolucionarios como uno acepta los hechos consumados". Hale, Emilio Rabasa, p. 114.

31 Podemos suponer que Goodman, enterado de las andanzas de los exiliados mexicanos, sabría el título y el pseudónimo de la publicación anónima del estudio si éste hubiese sido publicado en México o Estados Unidos. 
la Constitución de 1917. Además, como apunta Jaime del Arenal, este estudio es el único en el cual Rabasa trata

[...] con amplitud y cierta profundidad del "derecho de propiedad en general" con las consabidas referencias al derecho romano y al derecho castellano, es decir, al derecho civil, materia $\tan$ ajena y tan de poco interés a Rabasa [...] pero que se alinea a una creencia firme de nuestro autor: la propiedad es un tema, una institución y un problema que compete al Derecho civil, y punto. De aquí que vea como una intromisión la regulación constitucional. $^{32}$

Como era de esperarse por su origen, el texto El derecho de propiedad y la Constitución mexicana de 1917 está estructurado como una responsa romana, es decir, una forma de dar respuesta a una consulta muy específica y "con intereses muy definidos". ${ }^{33}$ El texto está dividido en cinco secciones: "El derecho de propiedad en general", "La propiedad del subsuelo y los contratos vigentes", "Capacidad legal de las compañías y de los extranjeros para adquirir y poseer bienes raíces", "Recursos legales contra los preceptos de la Constitución” y "La intervención diplomática”. De éstas, dos se refieren expresamente a temas que involucran intereses extranjeros. Una más lo hace indirectamente. ${ }^{34}$

En la primera sección del estudio Rabasa hace una recapitulación histórica de la forma en que se había establecido

32 Jaime del Arenal, comunicación personal, 9 de noviembre de 2015. Se cita con el permiso del autor.

${ }^{33}$ Jaime del Arenal, comunicación personal, 9 de noviembre de 2015. Se cita con el permiso del autor.

34 Jaime del Arenal, comunicación personal, 9 de noviembre de 2015. Se cita con el permiso del autor. 
el derecho de propiedad en México. Antes de 1917 México era una nación normal: "El estado del Derecho en México, ha sido en general, el que guarda en todo el mundo civilizado". ${ }^{35}$ El razonamiento positivista abre la reflexión sobre la propiedad: "la ley no es más que la representación por autoridad de las condiciones que impone por la fuerza un estado social previamente establecido. Son las leyes las que se derivan del estado social y es absurdo y tiránico forzar un estado social por medio de leyes". ${ }^{36}$

En consonancia con lo que escribió en La evolución histórica sobre la propiedad comunal, Rabasa afirmaba:

[...] las leyes españolas, derivación genuina de la ley romana, que adoptó casi en copia el famoso código de las Partidas, llevaron a México el régimen de la propiedad desde los días de la conquista, y siguieron en el país conquistando las mismas transformaciones, no muy profundas, que sufrieron durante los tres siglos de dominación. La forma atrasada de propiedad comunal, solo se conservó como medio de protección a la raza atrasada e improvisora. La independencia de México destruyó las diferencias jurídicas para las castas; la guerra civil llamada de Reforma (1858-1861) abolió la propiedad comunal y por los principios de libertad que en ambas guerras se proclamaron, el régimen de la propiedad quedó igualmente amplio, sin restricciones ni limitaciones en cuanto al sujeto y el objeto de aquel derecho fundamental. ${ }^{37}$

35 Rabasa, El derecho de propiedad, p. 1.

36 RaBAsa, El derecho de propiedad, p. 2.

37 Rabasa, El derecho de propiedad, pp. 3-4. 


\section{La Constitución de 1857 hizo}

[...] inviolable el derecho de propiedad, no sólo en la declaración directa de su artículo 27, sino en el 14, el 16 y en muchos más que lo protegen, por el procedimiento superior del recurso de amparo, contra cualquier acto de autoridad que lo viole, aunque la autoridad sea la más alta, y hasta contra las leyes que lo restrinjan, aunque procedan del Congreso Federal. ${ }^{38}$

La propiedad estaba garantizada en el orden jurídico. En efecto:

[...] un sistema de tribunales comunes ha estado siempre en funciones, bajo las reglas de procedimiento de códigos cultos que no desdicen en general de los de los países mejor administrados. Así, la propiedad en México ha tenido las garantías necesarias de respeto y de estabilidad contra los abusos o ligerezas del Poder público, y las seguridades contra la codicia privada que el orden social exige. ${ }^{39}$

No sólo las leyes establecían la propiedad: la "evolución histórica" habría impuesto límites al poder público y a los particulares. Así, "fuera de las leyes y con más fuerza que ellas, las costumbres habían dado en el estado social mismo la mejor garantía a la propiedad. Su violación o su amenaza de ejecutarla sublevaba las conciencias y movía indignación". ${ }^{40}$ Por esta razón, "la propiedad en México, tuvo hasta 1910, toda la amplitud, firmeza y la seguridad que puede exigirse al pueblo más culto de la tierra”. ${ }^{41}$

\footnotetext{
38 Rabasa, El derecho de propiedad. p. 4.

39 RaBASA, El derecho de propiedad, p. 4.

40 Rabasa, El derecho de propiedad, p. 5.

41 Rabasa, El derecho de propiedad, p. 5.
} 
Sólo un cambio constitucional radical podía afectar la manera en que estaba establecida la propiedad en México. La primera crítica a la transformación del régimen de la propiedad era que ésta había sido ilegítima, pues los procedimientos para reformar la Constitución de 1857 previstos en la misma carta no habían sido seguidos. El atropello constitucional era consustancial al proyecto revolucionario:

[...] este procedimiento consumía tiempo y entregaba a la publicidad y al influjo de la opinión pública las reformas propuestas y hacía imposibles las transformaciones radicales de forma agresiva contra el estado social. No había, así, más medio que el desconocimiento de la Constitución protectora, para atacar en el fondo el derecho de propiedad, y a él se apeló. Para expedir la constitución de 1917, ha sido necesario suponer la no existencia de la de 1857, que no ha sido reformada, como el título de la nueva dice por invocar su prestigio, sino simplemente desconocida. ${ }^{42}$

La Constitución de 1917 iba contra el estado social; era una forma de violentar el progreso civilizatorio alcanzado. Rabasa no ignoraba que muchas constituciones en la historia de las naciones habían tenido orígenes revolucionarios. Eso era cierto de la propia Constitución de 1857, que "desconoció" a la de 1824. De la misma manera, la Constitución federal de Estados Unidos no había respetado los procedimientos de los Artículos de la Confederación. Sin embargo, criticaba Rabasa, "una y otra buscaron apoyo en su propia sabiduría y no acudieron a subterfugios de legalidad

${ }^{42}$ Rabasa, El derecho de propiedad, p. 5. 
para crear un prestigio. Eran obra del espíritu nacional y no la imposición de la fuerza sobre los pueblos". ${ }^{43}$

En 1928 Rabasa volvería a tocar este punto en su curso de derecho constitucional. A sus alumnos les dijo que la carta de 1917 bordeaba peligrosamente con las constituciones "espurias" del siglo xix: las Siete Leyes centralistas de 1836 y las Bases Orgánicas de 1843. La característica central de esas constituciones "impuestas" era que habían durado muy poco tiempo. A 11 años de promulgada, la carta de 1917 bien podría correr la misma suerte, pensaba Rabasa. En efecto, aun con todos los defectos señalados en La Constitución y la dictadura, al paso de los años la Constitución de 1857 “iba tomando las características de una Constitución legitimada porque se iba acomodando al pueblo y, por su parte, el pueblo se iba acomodando a ella". La Constitución liberal "iba teniendo aplicación en la parte política, se iba aplicando en todo lo demás del organismo". Por ello, pensaba el jurista, cuando se hizo la Constitución de 1917,

[...]hubiera sido de desearse que fuera simplemente una reforma de artículos aislados, pero se hizo una Constitución completa y nueva, desde el primer artículo, hasta el último, recibiendo una aprobación especial de parte del Congreso constituyente y eso, en realidad, acabó con la constitución de 57 por más que se trató de hacerla promulgar el día 5 de febrero para que pareciera como una continuación de la de $57 .{ }^{44}$

Además de las anomalías en su génesis, la Constitución de 1917 en su artículo 27 había desprotegido a la propiedad. Y lo

${ }^{43}$ Rabasa, El derecho de propiedad, p. 6.

${ }^{44}$ Rabasa, "Curso de Derecho", p. 469. 
había hecho de una manera bastante peculiar. Había invadido los dominios del derecho civil para redefinir radicalmente el significado de propiedad. Así, la propiedad no era lo que se destilaba por la costumbre a lo largo del tiempo y quedaba plasmado en las leyes ordinarias, sino la invención de unos cuantos iluminados por dudosas teorías sociales. Así, "la constitución mexicana [de 1857] no hablaba en su breve artículo 27 de la propiedad, sino para garantizarla contra el atentado del poder o de las autoridades. Ese artículo, bajo el mismo número, se sustituye en la nueva con todo un tratado que cambia las bases de la propiedad del suelo, del subsuelo y de las aguas". ${ }^{45}$ Aquí está la clave para entender la afirmación pronunciada 11 años después de que el artículo 27 no era artículo, sino un tratado. A sus alumnos les dijo: "allí tenemos en esa Constitución el artículo 27 que es más un tratado que un artículo. Con sólo ese artículo se puede hacer un folleto". ${ }^{46}$

Ese tratado no sólo estaba fuera de lugar, sino que su contenido sustantivo era en extremo preocupante, pues instauraba la arbitrariedad en el texto constitucional. La Constitución no podría servir de salvaguarda al derecho de propiedad. En efecto:

45 Rabasa, El derecho de propiedad, p. 6.

46 Serra, Antología, p. 569. Mis cursivas. Este acto de desprotección, además, pensaba Rabasa, estaba redactado de manera muy deficiente. En su curso afirmó: “entre nosotros vemos el artículo 27 y encontraremos que se puede hacer en la propiedad todas las modalidades que quiere la nación y vemos la palabra 'modalidad' empleada por abogados en sentido de modificación, lo cual es enteramente distinto [...] el abuso de confianza es una modalidad del robo, esa es una expresión correcta, pero en el artículo 27 está empleada en lugar de modificación. Es tan disparatada como si dijéramos que la estafa es una modificación del robo". SERra, Antología, p. 592. 
Comienza el artículo declarando el principio general que va a servirle de fundamento: la propiedad de tierras y aguas es originariamente de la Nación, 'que ha tenido y tiene el derecho de transmitir el dominio de ellas a los particulares, constituyendo la propiedad particular'. 'La Nación', dice después, 'tendrá en todo tiempo el derecho de imponer a la propiedad privada las modalidades que dicte el interés público, así como el de regular el aprovechamiento de los elementos naturales susceptibles de apropiación, para hacer una distribución equitativa de la riqueza pública y para cuidar su conservación'. En teoría, estas declaraciones no hacen más que enunciar atributos de la soberanía que ninguna nación ha abandonado ni puede abandonar; es un principio simple de ciencia política, pero tiene limitaciones de cien principios más y que aquí no se toman en cuenta. El efecto de estas declaraciones en el cuerpo de la Constitución, es entregar la propiedad sin restricciones a la legislación común, despojarla de carácter de materia constitucional, y abandonarla a merced del Poder Legislativo originario, sin amparo en la Ley fundamental ni refugio en los tribunales federales. Por estas declaraciones, externadas en las demás del artículo 27, ninguna ley común que atente contra la propiedad del suelo puede ser inconstitucional, porque nunca podrá atentar contra la Constitución. Ahora bien, por tener México Constitución escrita, por la forma federal que establece categorías de leyes supremas y comunes, federales y locales, y por el estado moral que la experiencia revela en los órganos administrativos, nunca se considera garantizado un derecho que no esté fundamentalmente amparado en la Constitución nacional. ${ }^{47}$

El artículo, al estipular que la nación "tendrá en todo tiempo el derecho de imponer a la propiedad privada las

47 Rabasa, El derecho de propiedad, pp. 6-7. 
modalidades que dicte el interés público", no hacía sino establecer la arbitrariedad en la carta magna, que debía ser la salvaguarda de los derechos. Esta acción tenía una justificación ideológica: la redistribución de la riqueza. En efecto,

[...] la legislación común dispone de la propiedad privada a título de modalidades, "para la distribución equitativa de la riqueza pública y el cuidado de su conservación”, y dentro de estas elásticas medidas, cabe toda modalidad, que estará siempre dentro de la Constitución. Pero el artículo no es solo facultativo; es imperativo; previene al Poder público que dicte medidas (a) para fraccionamiento de latifundios, (b) para el desarrollo de la pequeña propiedad, (c) para la creación de nuevos centros de población agrícola, (d) para el fomento de la agricultura, (e) para evitar la destrucción de los elementos naturales, (f) para impedir los daños que la propiedad pueda sufrir en perjuicio de la sociedad. No hay atentado que no encuentre disculpa en alguno de estos motivos, que ya son por sí solos otros tantos atentados. ${ }^{48}$

La acción redistributiva acabaría por darle al gobierno un enorme poder discrecional y arbitrario sobre las personas. Ese poder sería, en el mejor de los casos, paternalista; en el peor, tiránico:

[...] dejando a un lado la realización del sueño socialista de distribuir equitativamente la riqueza (a que se han opuesto en los países más avanzados en desenvolvimiento moral, no solo el estado social, sino la naturaleza de las cosas), todos los motivos enumerados para las modificaciones de la propiedad privada

${ }^{48}$ Rabasa, El derecho de propiedad, p. 7. 
someten al propietario al capricho de las disposiciones que o los despojan o los ponen en tutela tal, que llegarán a necesitar del permiso de la autoridad para el uso de sus tierras. El daño que la propiedad recibe con el uso queda a la calificación de la ley y no del dueño; la destrucción de los elementos naturales (fauna y flora) se corregirá con reglamentos restrictivos; el fomento de la agricultura requerirá que cada propietario dedique sus tierras a un cultivo y prescinda de otros. Nada estorba que aun estos fines autoricen el despojo, puesto que el medio más seguro de realizarlos es quitar la tierra de las manos del dueño. ${ }^{49}$

Las constituciones liberales contienen protecciones contra el despojo. La tradición constitucional mexicana había producido un instrumento de tutela singular: el recurso de amparo. Sin embargo, la constitución lo neutralizaba en el caso de la propiedad. En efecto:

"La propiedad”, según el artículo, "no puede ser expropiada sino por causa de utilidad pública y mediante indemnización”; principio universal de derecho y único que contenía la Constitución de 57, y que en la nueva se expone por decoro y se destruye en seguida. La causa de utilidad pública, escrupulosamente determinada por la ley y con apelación a tribunales para su declaración, es lo único que puede justificar la expropiación; la indemnización es simplemente el pago de un precio justo para que el apoderamiento de la propiedad privada no se convierta en un acto criminal ejecutado en nombre de la utilidad pública. Pues bien, la condición primera se anula, en el mismo artículo que la establece, porque éste declara desde luego que los motivos enumerados para tomar la propiedad privada, se consideran de utilidad pública, y tanto el ser constitucionales,

${ }_{49}$ Rabasa, El derecho de propiedad, pp. 7-8. 
como su amplitud ilimitada, imposibilitan el recurso de amparo y todo otro medio de defensa por la vía judicial. [...] El procedimiento es sencillo y brutal: la autoridad administrativa hace la declaración de utilidad pública; no se provee recurso alguno contra una declaración ilegal o injusta. ${ }^{50}$

La indemnización a los propietarios expropiados era un triste remedio al despojo, pues se calculaba con el valor catastral, muy por debajo del valor de mercado, y además se obligaba a los propietarios a recibir bonos de una deuda especial de dudoso valor. ${ }^{51}$ Así,

[...] resulta de este examen, que la garantía declarada en favor de la propiedad individual queda burlada en sus dos condiciones de utilidad pública e indemnización, y que la expropiación legal se convierte en franco despojo. Y todavía hay que añadir la violencia constitucionalmente autorizada, prevenida, obligatoria para las autoridades judiciales y administrativas, que seguramente incurrirán en responsabilidad si no ejecutan el acto con la violencia ordenada. ${ }^{52}$

Los problemas jurídicos del artículo 27 eran numerosos. "Sería”, afirmaba Rabasa, "extender inconsiderada e inútilmente este estudio, detallar los numerosos amagos que falsean el derecho de propiedad en este artículo sin precedente, tanto en sus disposiciones directas como en sus inevitables consecuencias lógicas. Pero no pueden pasarse en blanco las

${ }^{50}$ Rabasa, El derecho de propiedad, p. 8

51 Rabasa, El derecho de propiedad, p. 9.

52 Rabasa, El derecho de propiedad, pp 9-10. 
principales y expresas". ${ }^{53} \mathrm{El}$ artículo declaraba nulos innumerables actos legales ocurridos desde 1856, incluidas sentencias, transacciones y enajenaciones. Se trataba de "sesenta y un años en que las propiedades han pasado de unas manos a otras con buena fe, $y$ en que se han transformado por el trabajo y la inversión de capitales". ${ }^{54}$ De la misma manera, eran

[...] revisables todos los contratos y concesiones de gobierno hechos desde 1876 acá, según el artículo 27, si han traído por consecuencia el acaparamiento de tierra, aguas y riquezas naturales por una persona o sociedad. El presidente de la República califica esta condición a su arbitrio, y declara la nulidad sin más requisito, sin indemnización de ningún género. Todos los contratos de deslinde de baldíos y venta de terrenos nacionales, quedan amenazados de nulidad y dependientes de la benevolencia del Presidente. ${ }^{55}$

No hay aquí lamentación alguna por el escaso poder del Poder Ejecutivo, que hizo a Rabasa famoso.

De forma similar, el cambio en el régimen de aguas negaba derechos adquiridos a propietarios. Las disposiciones anticlericales, pensaba Rabasa, no sólo afectaban al clero, cuyos prestanombres podían ser denunciados para confiscar sus

53 Rabasa, El derecho de propiedad, p. 10.

${ }^{54}$ Rabasa, El derecho de propiedad. "El artículo habla de restitución, lo que haría pensar que la privación debe haber sido ilegal para ameritar la nulidad; pero esto no es admisible, tanto porque para nada se expresa la condición de ilegalidad, como porque ésta no cabe en los casos de sentencia, de transacción y de enajenación expresamente comprendidos en la enumeración".

${ }^{55}$ Rabasa, El derecho de propiedad, p. 11. 
propiedades, sino a todos los propietarios en general. ${ }^{56} \mathrm{La}$ retroactividad era uno de los pecados de origen más graves del artículo 27. Eran tan flagrantes las violaciones que Rabasa afirmó: "para la propiedad no hay tribunales de justicia". ${ }^{57}$

Del estudio del artículo 27 de la nueva Constitución Rabasa sacaba las siguientes conclusiones:

$1^{\circ}$ Afecta desfavorablemente al sujeto de la propiedad territorial, porque niega la capacidad de adquirirla o conservarla a las sociedades por acciones, a los extranjeros que no renuncien su derecho de extranjería, y de un modo absoluto a todos los extranjeros en zonas prohibidas de grande extensión. $2^{\circ}$ Afecta el objeto de la propiedad porque limita la extensión de lo que un individuo o sociedad pueden poseer: porque restringe el dominio del subsuelo, priva de los derechos adquiridos sobre las aguas, y las exceptúa del dominio en las adquisiciones posteriores de tierras de la Nación. $3^{\circ}$ Afecta profundamente la extensión del derecho de propiedad, por la declaración expresa de reservarse la Nación la facultad de intervenir en la forma de aprovechamiento y conservación que el propietario emplee. $4^{\circ}$ Destruye la base de la propiedad, que es la seguridad de su firmeza, motivo que en las constituciones escritas la ha colocado entre las garantías individuales, al lado de la vida y de la libertad. $5^{\circ}$ Hace migatoria ${ }^{58}$ para la propiedad raíz la garantía del artículo 14, porque la garantía se da contra leyes y autoridades, $\mathrm{y}$ las leyes comunes y las autoridades administrativas tienen en el artículo 27, por vía de excepción, las facultades más amplías sobre la propiedad, con exclusión expresa de los tribunales. ${ }^{59}$

${ }^{56}$ Rabasa, El derecho de propiedad, pp. 11-12.

57 Rabasa, El derecho de propiedad, pp. 11-12.

${ }^{58}$ Migatoria, deshace.

59 Rabasa, El derecho de propiedad, pp. 13-14. 
El saldo de la innovación constitucional no podía ser más triste: "en virtud del artículo 27 de la nueva constitución (la propiedad) ha perdido los atributos que la constituyen en los pueblos civilizados de la tierra. En este sentido, que es el racional, puede decirse que la propiedad de la tierra ha dejado de existir en México". 60

En la segunda sección del estudio Rabasa se ocupa de la propiedad del subsuelo y los contratos. Hace una comparación de la legislación en diversos países como Francia, Estados Unidos, Rusia, Inglaterra, etc. Asienta que el sistema en que todas las sustancias minerales pertenecen al Estado "no está adoptado en ninguna parte" ${ }^{61}$ Rabasa reconocía que en todos los países la extensión de los derechos de propiedad sobre el subsuelo se veía limitada por las reservas impuestas por el Estado, "pero las leyes que después modifiquen esas limitaciones no están dispensadas de respetar los atributos fundamentales de la propiedad ya constituida sobre el subsuelo, como ninguna ley (ni las constitucionales) lo está de respetar todo derecho legítimamente adquirido". ${ }^{62}$

Rabasa analiza las disposiciones sobre minería en México desde la codificación de Gamboa de 1760 hasta la ley minera de 1909. Respecto al artículo 27, Rabasa afirma que la intención de "recuperar" el dominio parcial de las tierras que "salieron ya del dominio de la Nación" significaba

\footnotetext{
${ }^{60}$ Rabasa, El derecho de propiedad, p. 14.

${ }^{61}$ Rabasa, El derecho de propiedad, p. 16. Rabasa reconocía una tendencia clara: "Es notable también la tendencia de las diversas legislaciones a dar a la propiedad minera la independencia del Estado, que se desprende del dominio para dar al derecho privado los atributos de la propiedad inmueble, sin los cuales no hay estímulo ni confianza para empresas largas y costosas". ${ }^{62}$ Rabasa, El derecho de propiedad, p. 15.
} 
[...] un atentado tan desnudo como si privara a los propietarios de los árboles de sus bosques o de los pastos de sus llanuras. Solo la necesidad del análisis jurídico hace que, por tratarse de una ley, se considere en tal caso la disposición con el vicio de retroactividad, pues por lo demás, el despojo de la propiedad, hecho por autoridades no difiere del ejecutado por los particulares sino en la forma de violencia empleada, y el que los particulares hacen, según el Derecho Penal, no es más que una modalidad del robo. ${ }^{63}$

En efecto, "la propiedad de la tierra, que en principio procede del dominio eminente de la Nación, y que en realidad ha procedido siempre en México del dominio eminente del Estado, establece derechos adquiridos que forman parte del patrimonio de un individuo, y que salen de una vez para siempre del dominio nacional". ${ }^{64} \mathrm{El}$ alegato era claro:

[... si cada ley pudiera hacer en la propiedad constituida modificaciones que la cercenen en una proporción ilimitada, no le darían el carácter de perpetuidad, sin el cual la propiedad no existe; y si los títulos no tienen condición de irrevocables, no confieren el dominio, que es el único hecho jurídico que constituye la propiedad. ${ }^{65}$

Era evidente que los constituyentes deseaban actuar sobre derechos constituidos y no sólo reservar enajenaciones al futuro:

63 Rabasa, El derecho de propiedad, p. 22.

64 Rabasa, El derecho de propiedad, p. 22.

65 Rabasa, El derecho de propiedad, pp. 22-23. 
[...] lo demuestra el solo hecho de estar incluida en la ley fundamental una materia que no es constitucional y que siempre se encomendó a las leyes comunes. El objeto evidente de semejante anomalía es dar a la declaración carácter constitucional para que pueda ser retroactiva su aplicación sin violar la garantía individual del artículo $14 .{ }^{66} \mathrm{~A}$ resultas de esto todos los contratos y concesiones relativas al subsuelo habían quedado en una gran precariedad jurídica. ${ }^{67}$

Según Rabasa, "para romper los principios universales y tan antiguos como el Derecho de inviolabilidad de la propiedad y de no retroactividad de las leyes, la nueva Constitución se prepara con declaraciones de otros principios". La transgresión encontraba cubierta en "el dominio inalienable e imprescriptible de la Nación”. La conclusión de Rabasa era severísima: "el artículo 27 tiene la extravagante particularidad de estar colocado en el capítulo 'De las garantías individuales', cuando es un tratado de los derechos de la Nación contra la propiedad individual que desampara expresamente y destruye por su base". ${ }^{68}$

El tercer apartado del Derecho de propiedad y la Constitución mexicana de 1917 "se ocupa de la capacidad legal de las compañías y de los extranjeros para adquirir y poseer

${ }_{66}$ RaBASA, El derecho de propiedad, p. 23.

${ }^{67}$ En efecto, "todas las disposiciones del artículo 27 que afectan tan profundamente a la propiedad privada hasta quitarle los atributos que son su esencia, son inminente amenaza de los arrendamientos celebrados respecto al subsuelo, además de las agresiones de que son objeto los celebrados con la Administración respeto a tierras del dominio público o de las vendidas con reserva de los combustibles minerales". RABASA, El derecho de propiedad, p. 29.

${ }_{68}$ Rabasa, El derecho de propiedad, p. 23. 
bienes raíces". Aquí Rabasa analiza el artículo 27 como un tratado de "capacidad". En efecto, afirmaba:

[...] la capacidad para adquirir y poseer bienes raíces ha sido hasta hoy francamente amplia en México, que ha seguido en este punto el ejemplo de las naciones más liberales en la materia. Sólo las corporaciones civiles o religiosas han sido exceptuadas a la regla general que autoriza a individuos y sociedades para adquirir toda clase de bienes: y las leyes no han confundido nunca corporaciones y sociedades bajo una denominación, como lo hace la Constitución nueva en la fracción VII del tratado sobre capacidad que contiene el artículo 27.

La nueva constitución redujo las medidas de la capacidad, "ya por la naturaleza de las personas, ya por su nacionalidad, ya por la extensión de la propiedad". ${ }^{69}$ Menos agentes podían hacer menos cosas legalmente. Los extranjeros, los mexicanos que no lo fuesen por nacimiento y las sociedades por acciones estaban limitadas en su capacidad de adquirir propiedad. Rabasa señalaba que

[...] los individuos o sociedades extranjeras, no han tenido restricción ninguna en su capacidad de adquirir y poseer tierra, aguas, minas ni explotaciones del subsuelo en general, con la sola excepción que sustraen las dos zonas fronterizas de veinte leguas de ancho, salvo permiso del gobierno, que nunca se concedía a las sociedades anónimas.

Por ello, "la inclusión de las tierras es una novedad de trascendencia suma, extraña a la legislación sobre extranjeros de

${ }^{69}$ Rabasa, El derecho de propiedad, p. 30. 
casi la totalidad de las naciones cultas, y que dará lugar a la represalia que en muchos tratados vigentes se establece". ${ }^{70}$

No sólo la nacionalidad era un factor excluyente; también lo era la extensión. Y la restricción se estableció de un "modo general y, lo que es peor, indefinido", pues eran la federación y los estados los que definirían la extensión máxima de tierras que podrían adquirirse. ${ }^{71}$ El efecto era introducir una incertidumbre corrosiva en el régimen de propiedad:

[...] la facultad del Congreso y las Legislaturas para fijar la extensión permitida, no es transitoria, queda permanente dentro de la Ley fundamental rígida y perpetua; la ley que estime hoy medida justa 2000 hectáreas, puede modificarse el año próximo reduciendo la franquicia a 1000 , después a 500 , y también podrá, en vista de la experiencia, subirla a 5000, a 10000, cuando los despojos anteriores estén consumados. La incertidumbre, si no es propiamente una restricción de capacidad, destruye los efectos de la capacidad, puesto que nada significa la de adquirir un domino tan precario que no es en realidad dominio. ${ }^{72}$

Era innegable, afirmaba Rabasa, que cada estado soberano era libre para "modificar en sus leyes las bases de la propiedad privada y las reglas que tenga establecidas para otorgar concesiones y celebrar contratos con sus nacionales o con extranjeros". Sin embargo,

[...] la tendencia del Derecho en su progreso general, es dar a los extranjeros los mismos derechos civiles que las leyes de un

70 Rabasa, El derecho de propiedad, pp. 32-33.

${ }^{71}$ RaBasa, El derecho de propiedad, p. 31.

72 Rabasa, El derecho de propiedad, p. 32. 
país confieren a los nacionales. Desde las leyes o costumbres más antiguas, que negaban a los extranjeros todo derecho de propiedad, aun la inmueble, la evolución de los principios hacia la comunidad humana, ha llevado a las naciones de civilización cristiana a conferir a los extranjeros, por regla general, la propiedad raíz, con algunas restricciones en ciertos países para la explotación de minas, con absoluta libertad para el dominio de la tierra. ${ }^{73}$

La Constitución violaba tratados internacionales firmados por México, en particular la cláusula de nación más favorecida. Esas violaciones significaban no sólo un retroceso en cultura, "sino violar preceptos comunes del Derecho que rige las relaciones de la naciones que merecen el título de civilizadas" ${ }^{74}$ México iba a contracorriente de la civilización: “en México se dan dos pasos atrás para ponerse dentro del siglo XVIII, y esto no puede hacerse sin la reprobación de los países cultos y sin provocar su antipatía" ${ }^{75}$

En la última sección del estudio Rabasa consideró los riesgos de represalias por parte de potencias extranjeras a causa de la nueva constitución. Consideró que la cláusula de no intervención de los contratos sería a final de cuentas inefectiva contra países más poderosos. En efecto,

[...] la cláusula de no intervención, en que el extranjero renuncia su derecho de extranjería no puede importar la renuncia del derecho del Estado, que es también un deber, que le confieren las costumbres internacionales y que, admitidas y practicadas

73 Rabasa, El derecho de propiedad, p. 35.

74 Rabasa, El derecho de propiedad, p. 41.

75 Rabasa, El derecho de propiedad, p. 39. 
por todas las naciones, constituyen un principio del Derecho de gentes; poner la renuncia de una facultad del Estado como implícita en la que haga cualquiera de sus nacionales, es una pretensión absurda, puesto que supone al Estado subordinado en sus funciones internacionales al interés privado. ${ }^{76}$

\section{La cláusula era}

[...] indigna de figurar no ya en la Ley fundamental de un país, ni siquiera en una ley contrato; en primer lugar, porque como ineficaz para derogar los principios del Derecho de Gentes es ridícula como todo esfuerzo inútil que se funda en la fuerza de quien solo tiene debilidad; en segundo lugar, porque no tiene más objeto que adquirir la impunidad de los actos atentatorios y revela la determinación de cometerlos, la disposición de consentirlos y la imposibilidad de remediarlos por medio de una administración de justicia que no merece confianza al mismo Gobierno. $^{77}$

Constitucionalizar la cláusula había sido una imprudencia. El único efecto que surtía era el de “colocar a México en una posición peligrosa para su decoro, para su tranquilidad y aun para su integridad". ${ }^{78}$ Así, "la reclamación diplomática es el único medio de defensa contra los mandamientos de la Constitución; así lo ha querido la Constitución misma con poner obstáculos al recurso nacional de amparo, quitando a los atentados de las leyes y las autoridades el carácter de violatorios" ${ }^{79}$

${ }^{76}$ Rabasa, El derecho de propiedad, p. 54.

77 RaBASA, El derecho de propiedad, p. 54.

78 Rabasa, El derecho de propiedad, p. 60.

79 Rabasa, El derecho de propiedad, p. 60. 
Respecto a los recursos legales contra la Constitución, en principio había poco que hacer. Según Rabasa, en la antigua Constitución de 1857 la propiedad "tenía dos garantías constitucionales, que hoy simula conservar la nueva Constitución; una general contra leyes retroactivas, otra especial en su inviolabilidad declarada, salvo el caso de expropiación por utilidad pública, que reglamentarían las leyes" ${ }^{80}$ Esas garantías habían desaparecido. En efecto:

En ambos casos tenía que haber leyes secundarias que podían oponerse a los preceptos constitucionales relativos, que determinarían actos de ejecución, violatorios de una u otra garantía, y que, dando entrada al juicio de amparo, darían ocasión de intervenir a la Corte suprema, intérprete de la Constitución y autoridad constituida para la defensa de sus principios. La ley nueva altera esta situación, como si tratara de imposibilitar la defensa en los ataques que ella misma prepara dirigidos contra el derecho de propiedad, ya mediante las leyes que se expidan por la Federación o los Estados, ya por la ejecución inmediata de los actos que el artículo 27 autoriza. El recurso de amparo es el único que cabe contra actos o leyes que violen las garantías individuales, y si leyes y actos violatorios están prevenidos en la Constitución misma, el amparo será improcedente, porque la Constitución no puede violarse a sí misma. ${ }^{81}$

En el artículo 27 había preceptos que sólo eran inconstitucionales si se aplicaban de manera retroactiva, mientras que otros sencillamente ordenaban el "ataque a la propiedad”. Sin embargo, había una posible salida al beren-

${ }^{80}$ Rabasa, El derecho de propiedad, p. 43.

${ }^{81}$ Rabasa, El derecho de propiedad, p. 43. 
jenal constitucional, pensaba Rabasa: si el párrafo cuarto del artículo era interpretado de tal forma que sólo se pudiese referir al futuro (es decir, eliminando la posibilidad de su aplicabilidad retroactiva), entonces el amparo podría proceder. Así, intimaba Rabasa, "la Corte Suprema no tiene cerrado el camino de su jurisdicción". ${ }^{82}$ Sin embargo, el jurista no albergaba muchas esperanzas: "no hay que esperar con gran fe que la correcta interpretación sea aceptada, porque varias disposiciones y especialmente las del párrafo $3^{\circ}$ indican el propósito de no pararse ante la retroactividad". ${ }^{83}$

El artículo 27 surtía el efecto de derogar el artículo 14 de la Constitución En efecto:

[...] el artículo 14 dice que 'nadie podrá ser privado de [...] sus propiedades, posesiones o derechos sino mediante juicio seguido ante los tribunales previamente establecidos' [...] sufre una derogación que casi no puede llamarse parcial tanto por el párrafo $3^{\circ}$ como por los numerosos casos en que la propiedad

82 Rabasa, El derecho de propiedad, p. 44.

83 Rabasa, El derecho de propiedad, p. 44. "Anuncia éste que se dictarán las medidas necesarias para el fraccionamiento de latifundios para el desarrollo de la pequeña propiedad, y otros varios efectos que ocupan la propiedad privada: cada uno de estos motivos se considerará como de utilidad pública y la indemnización se apreciará mediante las reglas de despojo que señala el párrafo $8^{\circ}$. Ya no se requiere como condición para expropiar la previa indemnización que exigía la Constitución de 57; la nueva pide simplemente que se haga el apoderamiento de la propiedad privada mediante indemnización: en el despojo de los latifundios se hace, en efecto en veinte años. Si todas las prevenciones del párrafo $3^{\circ}$ fueran para aplicación futura, el párrafo quedaría sin ejecución de importancia, casi sin sentido racional; son, pues, de aplicación sobre la propiedad constituida en el presente, son francamente retroactivas y anuncian la aplicación al pasado de todas la que contiene el artículo 27 ”. 
no tiene defensa, no se dilucida en juicio, y se entrega a procedimientos administrativos de ejecución arbitraria, sin recurso ante los tribunales. Prevenidos esos procedimientos por la Constitución misma, no son violatorios de la garantía que infringen ni caen bajo la jurisdicción de la Suprema Corte. ${ }^{84}$

La consecuencia jurídica y política era apabullante: “el mandamiento que constituye en obligatoria la violación de la propiedad, por monstruoso que sea, no constituye violación constitucional ni permite la intervención de los tribunales". ${ }^{85}$

El “tratado" sobre la propiedad que era el artículo 27 no sólo estaba fuera de lugar en la carta magna; era profundamente nocivo. Emilio Rabasa lo dijo con todas sus letras:

La nueva Constitución mexicana no podía ser protectora de los derechos individuales, porque su espíritu es anticapitalista y antiextranjerista. Como enemiga del capital es hostil al derecho de propiedad y radicalmente socialista; como enemiga del extranjero es bóxer. ${ }^{86} \mathrm{Su}$ socialismo es de principios extremos, sin prudencia ni ciencia, hecho a pulso, no tanto para proteger a

${ }^{84}$ Rabasa, El derecho de propiedad, p. 45. "En este caso se encuentran las confiscaciones que a título de reivindicación determina la fracción II del párrafo 7 de bienes raíces y capitales impuestos sobre ellos, tuviera el clero por sí o por interpósita persona; las restituciones que ordena el párrafo 9o-, por leyes cuya ejecución se encomienda a la autoridad administrativa; el fraccionamiento de los latifundios y la anulación de contratos y concesiones de 1876 acá que es facultad conferida al Presidente de la República. En estos y otros casos la violación de los artículos 14 y 27 está no solo autorizada sino prevenida [...]".

${ }^{85}$ RaBASA, El derecho de propiedad, p. 45.

${ }^{86}$ Antiimperialista y xenófoba, se refiere Rabasa a la Rebelión de los Boxers en China en 1900. Agradezco a Manuel Patiño la observación. 
las clases populares, cuanto por destruir a las superiores; su animadversión para los extranjeros no es un nacionalismo determinado por sentimientos patrióticos erróneos, sino por rencor contra el capitalista extranjero, que abarca hasta los extranjeros sin capital. Y esto se impone en la constitución de un pueblo que no es ni socialista ni antiextranjerista, por medio de una presión encaminada a forzar el estado social en un cambio de condición radical, que desenvuelto por los demagogos ignorantes y explotadores, acabará por admitir y proclamar que todo es de todos y que los extranjeros son enemigos naturales como vampiros de la riqueza de la Nación. ${ }^{87}$

La palabra tiranía, empleada por Rabasa en su correspondencia personal, cobra aquí su cabal significación. La Constitución la establecía:

Para poner el atentado al abrigo de todo ataque legal ante los tribunales, la Constitución ha puesto en el artículo 27 que garantiza el derecho individual del Estado, la facultad y aun la obligación de violar los artículos que garantizan los derechos del verdadero individuo. En las disposiciones que ordenan la ejecución inmediata de una medida atentatoria, la retroactividad no tiene remedio, el recurso de amparo que se intente no tendrá base y los tribunales resolverán en contra y legalmente la improcedencia. En los preceptos que requieren ley reglamentaria para su aplicación o que en general puedan interpretarse como medida de aplicación futura, leyes o actos que les den efecto retroactivo, son remediables por el recurso de amparo. ¿Pero cuál será la interpretación que la Suprema Corte estime correcta? Si la Corte es lealmente revolucionaria, seguirá no los principios científicos de la interpretación, sino el espíritu de

${ }^{87}$ RabasA, El derecho de propiedad, pp. 50-51. 
la revolución claramente revelados en la Constitución nueva; pero suponiendo que quisiera sustentar los principios sanos, no tendrá libertad para hacerlo. ${ }^{88}$

La Constitución de 1917 no tenía los anticuerpos necesarios para combatir el mal que había sido sembrado en su estructura. La Suprema Corte, que en otras circunstancias podría haber servido como un contrapeso, había sido pensada de tal manera que no pudiera oponerse al Leviatán revolucionario. En efecto:

[...] es singular que una constitución que adopta el sistema de magistratura vitalicia para la Corte Suprema, convencida sin duda de su excelencia, la reserve para 1923, y prevenga para comenzar a ejercitarse el nombramiento de magistrados que durarán dos años los nombrados hoy y cuatro lo que se nombren en 1919. El objeto no puede exhibirse con más luz; se trata de que los magistrados no tomen en serio su independencia y de que sirvan al Gobierno de la revolución y no a la justicia. Una Suprema Corte cuyos miembros esperan su reelección o su eliminación del $1^{\circ}$ (primer) Congreso sumiso y en dos años, es imposible que interprete la Constitución y sostenga briosamente sus fallos en sentido que afecte los designios del Ejecutivo. En estas condiciones, hay que concluir que el recurso de amparo no tiene importancia legal efectiva como defensa de la propiedad contra los preceptos de la nueva Constitución. ${ }^{89}$

${ }^{88}$ Rabasa, El derecho de propiedad, p. 51.

${ }^{89}$ Rabasa, El derecho de propiedad, pp. 51-52. 
En los años que siguieron a su regreso a México, Rabasa evitó referirse públicamente a los aspectos políticos de la nueva constitución. En su condición de exiliado, la crítica tomó la forma de análisis jurídico institucionales de aspectos muy concretos. Sin embargo, salvo en algunos breves momentos de sus clases de derecho constitucional, Rabasa evitó referirse a los aspectos “sociales” del constitucionalismo mexicano.

La crítica de Rabasa a la Constitución de 1917 es la crítica a un ordenamiento dinámico, en movimiento, no a un texto fundacional estable. En efecto, la Constitución empezó a ser enmendada a los pocos años de ser promulgada, en un patrón transformativo que continúa hasta el día de hoy. Así, algunas de las críticas de Rabasa se refieren a las propuestas de reforma al texto original de 1917 que se consideraban al momento de escribir. Paradójicamente, Rabasa defendió algunos aspectos del texto original de Querétaro (el cual le pareció espurio en sus comienzos), contra transformaciones que consideraba ilegítimas. Aquí yace la ambigüedad de Rabasa frente a la Constitución de 1917.

Algunas de las innovaciones, a Rabasa le parecían desafortunadas. Por ejemplo, en 1921 escribió un artículo publicado en la Revista Jurídica de la Escuela Libre de Derecho en el cual criticó el procedimiento mediante el cual el Senado ejercía la facultad, conferida por los constituyentes de Querétaro, de designar al gobernador provisional de un estado cuando la gubernatura hubiese quedado acéfala (art. 76, fracc. V). Se trataba, creía el jurista, de un "procedimiento singular en que hay algo menos que malicia y algo más de 
inocencia". ${ }^{90}$ Para Rabasa, había un problema en la regla que estableció el constituyente de requerir una mayoría de dos terceras partes para dichos nombramientos. Mientras que Rabasa defendió en lo general la racionalidad de algunas votaciones que precisaran mayorías calificadas, consideraba un error que ese método se usara para elegir. En efecto, afirmaba Rabasa, "el sistema era racional y en muchos casos excelente; pero sólo aplicado a las votaciones que deben aprobar o reprobar: aplicado para elegir, como lo hace la Constitución de Querétaro, es modestamente absurdo y da y dará los frutos propios de lo absurdo". ${ }^{91}$ Por medio de este método, la minoría prevalecía sobre la mayoría, "no sirve para sostener algo establecido, es la simple voluntad, el capricho o el interés de los menos, sobreponiéndose a la voluntad del mayor número". De esa manera la minoría imponía al Ejecutivo la necesidad de proponer una nueva terna y burlaba "el mandato constitucional; y como con la segunda terna y la subsecuente puede una minoría obstinada repetir el procedimiento, el Estado acéfalo continuará sin gobierno, caerá en el desorden y en la anarquía". ${ }^{92}$ ¿Era ese el propósito deliberado de los constituyentes?, se preguntaba Rabasa. "Es de justicia creer que no. Por eso he dicho antes que esta disposición se adoptó con algo menos que malicia y algo más que inocencia". ${ }^{93}$

En el desarrollo histórico del constitucionalismo mexicano la carta de 1917, pensaba Rabasa, había continuado algunas tendencias heredadas de la Constitución de 1857. Si bien

$\begin{array}{ll}90 & \text { RabASA, “Una invención electoral”, p. } 228 . \\ 91 & \text { RABASA, “Una invención electoral”, p. } 229 . \\ 92 & \text { RaBASA, “Una invención electoral”, p. } 229 . \\ 93 & \text { RabASA, “Una invención electoral”, p. } 230 .\end{array}$ 
no era la causante del mal, sí lo había legitimado y profundizado. Era el caso de las deformaciones del papel del poder judicial y el juicio de amparo. Un mal que era de facto y que la Constitución volvió de jure.

En su intervención en el Primer Congreso Jurídico Nacional, celebrado en 1921, Rabasa criticó que la carta de 1917 hubiera sobrecargado de funciones a la Suprema Corte de Justicia. Le atribuía tareas que no podía cumplir de manera realista: “ ¿cómo hacer para que un solo hombre haga cada año el vestuario del ejército imperial?”. La respuesta era clara: "no hay medio ninguno". ${ }^{94}$ En virtud del artículo 107, la mayor parte de las resoluciones de los tribunales del país acababan en la Corte. Por ello los asuntos simplemente no podían desahogarse. "Si se quiere”, argüía Rabasa,

[...] como solución una reforma constitucional que permita al Alto Tribunal 'garantizar la rapidez de despacho' sin amenguar la tarea, el problema es igual al de contener el rebose del estanque sin reducir el surtidor, cuando es imposible ampliar el desagüe. Lo que la Constitución de 1917 hizo fue ampliar el surtidor en el artículo 107, como si la dificultad no hubiese existido nunca, como si el foro nacional no se hubiera dado cuenta jamás del estancamiento de la justicia en el tribunal que más altamente la imparte. ${ }^{95}$

En efecto, señalaba Rabasa, "el artículo 107 hizo constitucional y expresó lo que había sido hasta entonces malamente

${ }^{94}$ Rabasa, "La organización de la Suprema Corte y el Juicio de amparo", en Memoria del primer congreso jurídico nacional reunido en la Ciudad de México el 14 de septiembre de 1921 y clausurado el 12 de octubre del mismo año.

${ }^{95}$ Rabasa, "La organización de la Suprema Corte y el Juicio de amparo". 
consuetudinario o interpretativo, y quizá pueda yo decir que dio entrada legal a lo que antes andaba con las timideces de lo subrepticio". Los constituyentes de 1917, insinuaba Rabasa, habían olvidado o simplemente desconocían una verdad fundamental: la Suprema Corte no era un tribunal, sino un poder nacional supremo. ${ }^{96}$ La función de la Corte era siempre exclusivamente política: "como elemento regulador de la organización del gobierno". Su papel judicial procedía de atribuciones anexas, "adicionales, accidentales, no inherentes a su institución ni necesarias para su objeto”. Para Rabasa:

[...] la Corte Suprema fue instituida como poder limitador de los poderes nacionales; para ceñirles en el círculo de sus atribuciones legítimas; para levantar ante cada uno de ellos las barreras de la Constitución con los derechos individuales que fundan la soberanía popular, con la división de poderes que previene el despotismo, con la delimitación de las competencias que asegura la libertad de los Estados y el régimen federal [...] Esto no es un tribunal, es el Poder de resistencia que ampara la obra de la soberanía nacional. ${ }^{97}$

Aquí la crítica a los constituyentes de 1917 es indirecta, pero bastante clara y contundente. Tal vez la práctica del régimen constitucional durante el periodo de vigencia de la carta de 1857 hubiese sido censurable por la hipertrofia de facto del sistema que había producido (mediante la jurisprudencia de algunas Cortes imprudentes), pero los hombres que forjaron esa constitución tenían mucho más clara la función de la Suprema Corte y del amparo que los de Querétaro. En

96 Rabasa, "La organización de la Suprema Corte y el Juicio de amparo". 97 Rabasa, "La organización de la Suprema Corte y el Juicio de amparo". 
efecto, para Rabasa, los constituyentes de 1856-1857 comprendieron que el sistema de gobierno que crearon estaba basado en la supremacía del poder judicial: "supremacía que se hace efectiva por medio del juicio constitucional. Así lo entendieron los legisladores del 57 y sistemaron el amparo con una precisión que aún no admiramos lo bastante”.

Dos años después Rabasa repetiría esta tesis sobre la degeneración legal del recurso de amparo con mayor claridad:

[...] hoy todo el mundo sabe que el juicio de amparo es un recurso último cuyo objeto es detener el curso de la justicia común de un modo fácil y por tiempo indefinido. La constitución de Querétaro confirmó absolutamente la nueva teoría del amparo, incluyendo en sus artículos una reglamentación tan impropia de una ley fundamental como inadecuada para texto de buen castellano en las escuelas rurales.

De la atrofia de la Corte, inundada de recursos, "no tiene la culpa la Corte, sino la constitución, la ley orgánica, los vicios de práctica, la mala organización del tribunal”. ${ }^{98}$

Las propuestas de dividir a la Suprema Corte en salas trabajarían, creía Rabasa, contra su autoridad moral y política. El pasado decimonónico era claramente superior. En efecto, la Corte de Vallarta, "en su breve existencia comenzó a formar un cuerpo de precedentes que se impuso a los jueces y respetaron los letrados, no por ley conminatoria ni por cuenta de tendero, sino por la autoridad de aquel cuerpo que siempre supo ser el Poder Judicial, un Poder

98 Emilio Rabasa, "Sobre la Suprema Corte. Cuarto artículo. El amparo y la Corte", Excelsior (19 mayo 1923). 
Supremo entre los Supremos Poderes". ${ }^{99}$ Como para Rabasa la tendencia de que la justicia tuviese la última palabra en un tribunal central era claramente irreversible, la solución estaba en la creación de una corte de casación de acuerdo con el modelo francés. El lugar del Poder Judicial, el control de la constitucionalidad y la protección de los derechos individuales, son temas que recorren el amplio arco de la reflexión jurídica y política de Rabasa. Estas preocupaciones lo ocuparon por lo menos desde 1906 y se extendieron hasta el final de su vida. De ello dan cuenta sus trabajos El artículo 14 y El juicio constitucional. ${ }^{100}$

Dos años después de su intervención en el Congreso jurídico nacional, Rabasa escribió una serie de artículos periodísticos en relación con las propuestas que se discutían entonces para enmendar la Constitución, que establecía la inamovilidad de los ministros de la Suprema Corte. Este era un tema que le era cercano a Rabasa desde hacía mucho tiempo.

El 9 de mayo de 1923 Rabasa reconoció que, en dos ocasiones, antes de 1917, la idea de hacer inamovibles a los "altos funcionarios de la justicia federal" había estado a punto de volverse realidad: en 1892 y en 1911. En ambas ocasiones el proyecto había naufragado en el último instante debido a la misma causa: la animadversión del Poder Ejecutivo hacia un poder autónomo. En este punto coincidían tanto la dictadura de Díaz como la democracia de Madero.

\footnotetext{
99 Rabasa, "La organización de la Suprema Corte y el Juicio de amparo". 100 Uno de estos textos, El artículo 14, fue escrito antes de la promulgación de la Constitución de 1917 (en 1906) y el otro, El juicio constitucional, fue publicado dos años después, en 1919. Rabasa, El artículo 14. Estudio constitucional y el juicio constitucional.
} 
"Y es que", reflexionaba Rabasa,

[...] las garantías de la libertad no se han de pedir nunca al poder, sino que han de imponérsele. La psicología política lo demuestra con razonamiento incontestable y la historia constitucional de los pueblos libre lo confirma con hechos. Al forjarse la Constitución de 1917, el poder inseguro y vacilante tenía más de criado socarrón que de amo altivo.

El amo de la situación era la Revolución, no el gobierno. Esa fue la coyuntura excepcional que en Querétaro permitió a las "garantías de la libertad" prevalecer en el tercer intento. El Congreso Constituyente,

[...] que al decir de entonces y al decir de hoy, encarnó y vitalizó en su ley los ideales revolucionarios, enclavó en la ley rígida, perdurable y casi inconmovible, la inamovilidad de los jueces. La garantía de la justicia independiente llegaba al fin al triunfo y llegaba por el proceso normal e histórico; no pedida como una concesión del poder, sino arrancada a la omnipotencia tradicional que tenía raíces seculares en el concepto del poder público, en las preocupaciones profesionales siempre timoratas y sabihondas y hasta en la conciencia vulgar, tan resistente a toda innovación transformadora de las viejas costumbres. ${ }^{101}$

Sin embargo, aquella circunstancia tan excepcional no podía durar mucho tiempo. Y la Revolución hecha gobierno volvió a comportarse como se comportan todos los gobiernos conocidos. En efecto: "reaparece una especie de

101 Emilio Rabasa, "Sobre la inamovilidad de la Suprema Corte. Primer artículo", Excelsior (9 mayo 1923). 
conservatismo por coquetería, algo como un anacronismo aristocrático, como la ostentación de una prenda arcaica sacada del arcón viejo de la familia linajuda”. Y por un momento se asoma la amargura del antiguo exiliado, que había sido sorprendido por la osadía de los constituyentes de Querétaro al arropar una de sus más queridas causas, sólo para verla tambalearse al poco tiempo antes de su consumación:

[...] la suprema conquista de la revolución, que tan pocas cuentas en su abono y tantas partidas tiene en su cargo, parece ahora, como a la dictadura en 1892 y al apostolado en 1911, inoportuno, peligroso para la sociedad, amenazador del bien público. El gobierno propone en larga iniciativa de reformas numerosas a la flamante constitución, que encarnó y justificó a la revolución destructora, que se deroguen los artículos que implantaron como promesa para 1923 la inamovilidad de los jueces y que se sustituya con este sencillo sistema, simple y fácil como todo sistema dictatorial: los jueces durarán en su encargo muy poco tiempo y serán nombrados por el Ejecutivo; es decir, estarán a la disposición del Ejecutivo a toda hora y para todo servicio. ${ }^{102}$

Como hemos visto, la razón ya la había expuesto en 1917: "una Suprema Corte cuyos miembros esperan su reelección o su eliminación del Congreso [...] es imposible que interprete la Constitución y sostenga briosamente sus fallos en sentido que afecte los designios del Ejecutivo". ${ }^{103}$

Rabasa aquí, paradójicamente, defendía a la Constitución de 1917 de sus artífices revolucionarios. En efecto, el

102 Emilio Rabasa, "Sobre la inamovilidad de la Suprema Corte. Primer artículo”, Excelsior (9 mayo 1923).

103 Rabasa, El derecho de propiedad, pp. 51-52. 
artículo 94 de la carta de 1917 preveía un sistema escalonado para implementar la inamovilidad de los jueces. La disposición estaba concebida en estos términos:

Cada uno de los Ministros de la Suprema Corte designados para integrar ese Poder, en las próximas elecciones, durará en su encargo dos años; los que fueren electos al terminar este primer período, durarán cuatro años y a partir del año de 1923, los Ministros de la Corte, los Magistrados de Circuito y los Jueces de Distrito sólo podrán ser removidos cuando observen mala conducta y previo el juicio de responsabilidad respectivo, a menos que los Magistrados y los Jueces sean promovidos a grado superior. ${ }^{104}$

Rabasa combatió las razones de la iniciativa de reformas del gobierno. Alegó con enjundia que era falso que la inamovilidad de la magistratura requiriera como base una "gran cultura en el pueblo". ${ }^{105}$ Argüía que la inamovilidad no tenía nada que ver con "la cultura general de un pueblo”. Una función, argumentaba, "necesita conocimiento $y$ aptitud por parte de quien la ejerce; pero no por parte de quienes reciben sus beneficios”. El pretexto culturalista del despotismo frustraba a Rabasa:

[...] para nosotros el tiempo oportuno no llega nunca. Para otros pueblos la inamovilidad fue oportuna y benéfica desde hace siglos; desde cuando eran casi rudos y casi absolutamente ignorantes, pero nosotros debemos seguir esperando a que

104 Marván, Nueva edición del Diario de debates, p. 2037.

105 Emilio Rabasa, "Sobre la inamovilidad de la Suprema Corte. Segundo artículo. La inamovilidad y la cultura”, Excelsior (12 mayo 1923). 
nos transformen la instrucción pública y las reformas sociales al través de una docena o dos de buenos siglos. ${ }^{106}$

La puesta en ejecución del sistema escalonado para instaurar la inamovilidad de los magistrados que adoptó la Constitución de 1917 demostraba que, si bien una magistratura independiente era posible, representaba una molestia para los otros poderes. Los primeros ministros de la Corte duraron sólo dos años. Concluido ese "periodo, dosimétrico, no sé si las legislaturas al proponer candidatos, o el Congreso al hacer su selección, dejaron fuera de la lista a los tres ministros que más se distinguieron por sus notables condiciones de altos jueces: independencia, sabiduría, honradez, empeño en el trabajo". ${ }^{107}$ La Constitución de 1917 aventuró una promesa tímida de futura independencia judicial, pero la promesa no se cumplió. El comienzo había sido feliz; según Rabasa, “en la Corte que se va ha habido una mayoría de hombres útiles, honrados, de buena fe [...] si el propósito de la Constitución en sus pruebas cortas se tomara en serio, habría ya un grupo de ministros escogidos y experimentados, base para una Corte que nada tendría que envidiar a la que presidió don Ignacio L. Vallarta”. ${ }^{108}$

Rabasa se enfrentaba así a un defecto del régimen revolucionario: para adaptarse y consolidarse debía destruir y

106 Emilio Rabasa, "Sobre la inamovilidad de la Suprema Corte. Segundo artículo. La inamovilidad y la cultura”, Excelsior (12 mayo 1923).

107 Emilio Rabasa, "Sobre la Suprema Corte. Tercer artículo. Los que se van y los que llegan”, Excelsior (16 mayo 1923). Rabasa se refería a los magistrados Pimentel, Colunga y Cruz.

108 Emilio Rabasa, "Sobre la Suprema Corte. Tercer artículo. Los que se van y los que llegan”, Excelsior (16 mayo 1923). 
recrear la constitución a cada paso. Entreveía el fenómeno de la constitución inerme. La carta magna no iba a contener al régimen; el régimen iba a contener a la constitución por medio de reformas que negaban su carácter de norma fundamental rígida. La inamovilidad, que había sido entronizada por los constituyentes de 1917 , iba a ser desechada muy poco tiempo después.

¿Podía el gobierno faltar a su promesa de inamovilidad y arrojar de sus puestos a los magistrados que fueron nombrados como vitalicios? Sin duda, respondía Rabasa. Sin embargo, al hacer esto el Estado faltaba a uno de los deberes para consigo mismo y para la nación, deberes que le imponían

[...] la necesidad de respetar sus leyes para que estas se vean siempre como algo firme, inconmovible y hasta inevitable; para que el Estado sea tenido por el pueblo que encarna como una entidad que limita su omnipotencia con las restricciones de su decoro y sus leyes constitucionales como promesas que sellan montañas de granito. ${ }^{109}$

El 20 de agosto de 1928, cinco años después de que Rabasa escribiera estas líneas, se reformó el artículo 94 y se removió a los magistrados. Algunos años más tarde, en 1934, el artículo fue reformado por segunda vez y el periodo del nombramiento de los ministros de la Corte, los magistrados de circuito y los jueces de distrito se estableció en seis años. $^{110}$

109 Emilio Rabasa, "Sobre la Suprema Corte. Tercer artículo. Los que se van y los que llegan”, Excelsior (16 mayo 1923).

110 Congreso de la Unión, Cámara de Diputados, L Legislatura, Los derechos del pueblo mexicano, pp. 706-707. El 13 de abril de 1928 
En 1930, siete años después de su reflexión original, Rabasa era más duro con el régimen revolucionario:

[...] la Constitución de 1917 vino a realizar una idea seguramente benéfica para las instituciones nacionales [...] la inamovilidad de los miembros de la Suprema Corte de Justicia; pero este acierto de los legisladores del año 17 fue no sólo deslucido, sino más que anulado, porque tuvieron la desgraciada ocurrencia de atribuir el nombramiento de los Ministros de la Corte al poder político por excelencia (el Gobierno de la Unión), siendo así que la condición esencial de la alta magistratura consiste en su aislamiento absoluto contra toda influencia de la política activa. Tuvo también aquel congreso la singular y originalísima idea de no hacer la inamovilidad de un solo golpe, sino que,

Rabasa les dijo a sus alumnos en su curso de Derecho Constitucional en la Escuela Libre de Derecho: "La Constitución de 1917 estableció la inamovilidad judicial en una forma muy singular, porque es verdaderamente candorosa [...]. La primera Corte fue una cosa notable; la primera Corte solamente tiene como precedente la Corte de Vallarta gracias a que hubo tres personas que yo siempre nombro [...] Terminaron los dos años; el Congreso hizo nuevos nombramientos excluyendo precisamente a los tres que he mencionado [...] En la segunda Corte aparecieron dos o tres miembros buenos. En la elección de la tercera Corte de los inamovibles, los buenos fueron excluidos. De manera que el resultado ha sido inverso, ya que se buscaba a los mejores para que no volvieran a ser electos. Llegan por fin los inamovibles y, en primer lugar, sucede que no tienen la seguridad de la inamovilidad, de manera que las ventajas de la inamovilidad se pierden [...] En realidad, los jueces no son inamovibles. [...] No es la condición de la inamovilidad de los jueces lo que hace que la Administración de justicia no sea buena. Es probablemente por el sistema de elección que convierte en elección política lo que debería ser elección ordenada, juiciosa y hecha en vista del orden público [...] vamos, pues, mal en materia de inamovilidad, y mientras no tengamos inamovilidad no podremos tener seguridad en la independencia de los jueces". Rabasa, "Curso de Derecho Constitucional”, pp. 435-437. 
según los preceptos que se establecieron, habría que realizarse poco a poco. ${ }^{111}$

Para Rabasa, el resultado de estos procedimientos,

[...] fue tan lamentable como todos saben, hasta que llegó la reforma constitucional propuesta por el general Obregón, que al cambiar el sistema de nombramiento de los Ministros de la Suprema Corte aprovechó la ocasión para remover a los vitalicios, sin perjuicio de la inamovilidad en que, conforme al artículo reformado, debemos seguir creyendo. ${ }^{112}$

Rabasa pensaba que el problema era el método de selección de los magistrados, no la inamovilidad. Los magistrados deberían ser designados por el Ejecutivo, con ratificación del senado, como en Estados Unidos, y no electos por el Congreso, como estableció la Constitución de 1917.

En los dos últimos años de su vida Rabasa volvió a ocuparse de la Constitución de 1917 en su quehacer periodístico. Lo hizo en 1929, en la víspera de las elecciones presidenciales de ese año, para discutir aspectos electorales. ${ }^{113}$ En algunos

${ }_{111}$ Emilio Rabasa, "La Asamblea Nacional”, Excelsior (25 y 26 jun. 1930), reproducidos en SErra, Antología, pp. 299-304. Rabasa ironizaba: "Hacer la inamovilidad poco a poco y ejercitar al pueblo para llegar a tenerla, es algo de una inocencia tan pueril como si para preparar a una persona al sueño eterno se le aplicara primero una dosis de Veronal para veinte horas de sueño, después una serie de brebajes para dormir veinte días, para terminar con una dosis de morfina suficiente para que no despertara nunca".

112 Emilio Rabasa, "La Asamblea Nacional”, Excelsior (25 y 26 jun. 1930), en Serra, Antología, p. 300.

113 Emilio Rabasa, “Un vacío peligroso", Excelsior (15 y 25 nov. 1929), reproducidos en SERra, Antología, pp. 283-286. 
asuntos la Constitución de 1917 simplemente había continuado, para bien o para mal, las tendencias de la carta que le precedió. Ese era el caso de la elección presidencial. A pesar de que los constituyentes de 1856-1857 habían copiado muchas de las provisiones de la Constitución estadounidense, argüía Rabasa, inexplicablemente no habían seguido a los estadounidenses en regular, en la propia carta magna, lo que debía hacerse en el caso de una elección presidencial en la cual hubiera más de dos candidatos y ninguno de ellos obtuviera la mayoría absoluta de votos. Los estadounidenses le dieron a la Cámara de Representantes el poder de elegir al presidente de entre los tres candidatos que hubiesen obtenido más votos. En cambio, los mexicanos en 1857 consignaron esa facultad en una ley secundaria, la ley electoral. La Constitución nunca se enmendó para corregir este vacío. En cuanto a los constituyentes de 1917, "que hicieron profundas innovaciones en nuestro derecho constitucional, parece que no creyeron útil la lectura de la Constitución norteamericana y tampoco remediaron el error cometido desde 1857". ${ }^{114}$

El problema era que las leyes electorales que facultaban al Congreso para elegir presidente eran, de acuerdo con Rabasa, notoriamente inconstitucionales y nulas, pues "de ningún modo puede el Congreso en una ley de este género ni restringir la facultad otorgada en la Ley Suprema, ni modificarla, ni mucho menos ampliarla en términos que constituyan una función nueva que no esté expresamente señalada en la Constitución”. ${ }^{115}$ La ley electoral, en opinión de Rabasa,

114 Emilio Rabasa, “Un vacío peligroso”, Excelsior (15 y 25 nov. 1929), en Serra, Antología, p. 284.

115 Emilio Rabasa, "Un vacío peligroso", Excelsior (15 y 25 nov. 1929), en Serra, Antología, p. 285. 
[...] no solamente atribuye al Congreso una facultad nueva, sino que lo dota con una función notoriamente grave, puesto que sustituye en realidad al voto público al designar o nombrar al presidente de la República de entre dos que no han llegado a reunir la mayoría del voto popular. Cómo es que un Congreso Constituyente en que había hombres como Arriaga, Mata, Guzmán y otros muchos de gran talla, pudo incurrir en el error de dejar el precepto de la Constitución americana para la Ley Electoral y no incluirlo en el cuerpo de la Ley Suprema, es algo que no se explica como tampoco se explica que el error haya perdurado al través de múltiples reformas y de una Constitución nueva. ${ }^{116}$

En el siglo xix la ausencia de enmiendas se explicaba por una realidad de suyo triste: "los grandes problemas constitucionales en México se han resuelto a tiros”.

Otro asunto relacionado con el titular del Poder Ejecutivo preocupaba a Rabasa. Se trataba de la disposición de la Constitución que regulaba la operación de las reuniones plenarias del Congreso Federal. Rabasa combatía una interpretación según la cual no podía considerarse constituido el Congreso sino cuando contara cada una de las dos cámaras con su quórum reglamentario.

La confusión, alegaba Rabasa, se remontaba a una reforma constitucional del porfiriato. Díaz deseaba evitar un sistema de designación individual. En efecto, en 1896 se enmendó la Constitución para que el Congreso Federal nombrara al presidente provisional en caso de falta del titular del Poder Ejecutivo. De acuerdo con esa reforma, el Congreso de la

116 Emilio Rabasa, “Un vacío peligroso”, Excelsior (15 y 25 nov. 1929), en Serra, Antología, p. 286. 
Unión quedaría instalado con más de la mitad del número de total de los individuos de ambas cámaras. Según Rabasa, "de aquella reforma hecha en 1896 fue a tomar su precepto relativo la Constitución de Querétaro que, en mi concepto, por una preocupación ilógica, se negó también como el general Díaz, a individualizar al substituto posible del Presidente de la República". ${ }^{117}$ Así, de acuerdo con el artículo 84 de la carta de 1917, en caso de falta absoluta del presidente ocurrida en los dos primeros años del periodo respectivo, el Congreso se constituiría en Colegio Electoral y, concurriendo cuando menos las dos terceras partes del número total de sus miembros, nombraría al sustituto. Rabasa pensaba que la interpretación según la cual se requería que cada cámara contara con dos tercios de sus miembros para reunir el quórum estaba equivocada, a pesar de ser la interpretación dominante sobre el tema. En efecto, se quejaba Rabasa,

[...] según la falsa interpretación que tan dócilmente han aceptado nuestros representantes, bastaría que veinte senadores se pusieran de acuerdo para obligar al Congreso a someterse a sus caprichos o a celebrar transacciones indebidas o a crear una situación sin solución posible [...] en el caso de una elección presidencial podría dar lugar la repetición del caso a un estado lleno de peligros, como provocaciones casi seguros de una revolución general. ${ }^{118}$

117 Emilio Rabasa, "Un vacío peligroso", Excelsior (15 y 25 nov. 1929), en SERra, Antología, p. 303. Con la diferencia, hacía notar Rabasa, de que en lugar de una mayoría simple la Constitución de 1917 requería de las dos terceras partes de los diputados y senadores reunidos.

118 Emilio Rabasa, "Un vacío peligroso", Excelsior (15 y 25 nov. 1929), en SErra, Antología, p. 303. 
En suma, la interpretación del artículo constitucional -o el artículo mismo - era una receta para la ingobernabilidad. Dada la ausencia de debate sobre el sentido del artículo 84, Rabasa concluía que "el artículo 84 es un perpetuo peligro y que habrá de conducirnos un día a una conflagración nacional [...] Y esto lo que significa es que el artículo debe ser modificado y que urgentemente requiere una redacción nueva, que ponga en manos de la Representación Nacional la elección del Presidente". ${ }^{119}$

Finalmente, Rabasa pensaba que había sido un error de los constituyentes de Querétaro la eliminación de la vicepresidencia. En dos artículos de 1930, publicados en Excelsior, alegó que era imposible encontrar un sistema más adecuado para sustituir al presidente en sus faltas absolutas. ${ }^{120}$ Después de hacer un análisis histórico de los diferentes métodos de sustitución, Rabasa llegaba a una conclusión: un régimen de gobierno basado en un presidente fuerte, que era el único que había provisto de estabilidad a México, requería un sistema de sustitución en el cual el poder migrase, de manera casi automática, a otro hombre fuerte. Y utilizaba una hipótesis contrafactual: si Díaz, cuando contaba con 74 años, después de reformar la Constitución y restablecer la vicepresidencia, hubiese muerto antes de concluir su periodo, "la sustitución del Jefe del Ejecutivo se habría verificado tan llana y tranquilamente como la de 1872; porque la legitimidad infunde siempre respeto, aun cuando aquella

119 Emilio Rabasa, “Un vacío peligroso”, Excelsior (15 y 25 nov. 1929), en Serra, Antología, p. 304.

120 Emilio Rabasa, "El desprestigio de la vicepresidencia”, Excelsior (3 y 4 abr. 1930), reproducidos en SERrA, Antología, pp. 304-309. 
sea meramente formal, aun en los pueblos poco sometidos a las disciplinas políticas". ${ }^{121}$ Por eso la conclusión

[...] a que se llegó en virtud de la revolución de 1910 y la consecuente de 1914, fue absolutamente falta de lógica: se declaró que la institución de la Vicepresidencia fue la causa del derrumbe del Gobierno del general Díaz, y que es una institución perversa, dañina y rebelde, enteramente inadecuada para el pueblo mexicano. ${ }^{122}$

El problema no era la vicepresidencia, sino lo defectuoso de su diseño institucional en la historia del país. La vicepresidencia de la Constitución de 1824, así como la que se restableció en 1904, tomaron formas inapropiadas. En 1824 el diseño era una receta para el conflicto faccional (el vicepresidente era el candidato a la presidencia que había quedado en segundo lugar) y en 1904 el vicepresidente podía ser también ministro y ejercer cargos públicos. Ambos diseños eran innovaciones desafortunadas al modelo estadounidense. Así, concluía Rabasa, "si la causa determinante de la Revolución de 1910 fue por lo menos al principio, la imposición del Vicepresidente para el nuevo periodo, en ello no tuvo que ver la institución de la Vicepresidencia, sino simplemente la imposición de una persona”. ${ }^{123}$

121 Emilio Rabasa, “El desprestigio de la vicepresidencia”, Excelsior (3 y 4 abr. 1930), en SERra, Antología, p. 306.

122 Emilio Rabasa, "El desprestigio de la vicepresidencia”, Excelsior (3 y 4 abr. 1930), en SErra, Antología, p. 307.

123 Emilio Rabasa, "El desprestigio de la vicepresidencia”, Excelsior (3 y 4 abr. 1930), en Serra, Antología, p. 309. 


\section{CONCLUSIÓN}

En un discurso pronunciado en 1935 en la Escuela Libre de Derecho, cinco años después de la muerte de Emilio Rabasa, Felipe Tena Ramírez dijo sobre su maestro: "Rabasa aplicó a nuestras instituciones las ideas liberales, esencialmente los tres grandes principios constitucionales que el partido liberal inscribió en su bandera a través de nuestra historia: la soberanía popular, el sistema federal y los derechos individuales". Sin embargo, Tena se lamentaba, los tiempos habían cambiado: "la decepción por la libertad, producida por las pavorosas consecuencias de la guerra y la posguerra, ha interrumpido el proceso del constitucionalismo". ${ }^{124}$ El liberalismo en esos años se hallaba en su punto más bajo y los totalitarismos iban en ascenso. "De aquellas teorías", decía Tena, "en cuya elaboración se esmeraron varias generaciones y que inspiraron a Rabasa sus mejores páginas, sobra bien poco en el acervo de la especulación constitucional. Su raíz era la libertad, y de la libertad ya no queda sino la desilusión". ${ }^{125}$

La carta de Querétaro no puede comprenderse como un desarrollo del constitucionalismo liberal, como lo definía Tena: "realización de garantías y de libertades". ${ }^{126}$ Disipada la ilusión tan bien construida por don Jesús Reyes Heroles, de que la revolución mexicana - y su constitución - era la continuación necesaria y natural del liberalismo decimonónico, la posición crítica de Rabasa recobra parte de su sentido. ${ }^{127}$

\footnotetext{
124 Tena, Silueta de don Emilio Rabasa, p. 26.

125 Tena, Silueta de don Emilio Rabasa, p. 25.

126 Tena, Silueta de don Emilio Rabasa, p. 26.

127 Reyes Heroles, El liberalismo mexicano. Véase también GarciadieGO, “¿Dónde quedó el liberalismo?”.
} 
Sin duda, podemos leer a Rabasa en clave de constitucionalismo oficial. Es decir, la Constitución vista como una "síntesis de las grandes gestas históricas, el agregado de conquistas sociales, la suma de los factores reales de poder, el resumen de nuestro Proyecto Nacional, las decisiones esenciales del Pueblo". ${ }^{128}$ Tena en su elegía ilustra bien esa posibilidad:

[Rabasa] fue inspirador, en el aspecto de la técnica jurídica, de la Constitución de 17. Honor para el hombre que desde el destierro, por medio de sus libros, supo hacerse escuchar por una convención revolucionaria; pero honor también para los constituyentes de Querétaro, que tuvieron el patriótico ademán de aceptar las opiniones del proscrito. ${ }^{129}$

Sin embargo, esta apropiación de Rasaba por parte del constitucionalismo oficial sólo resulta plausible si ignoramos lo que el propio Rabasa dijo y escribió sobre la Constitución de 1917. Durante 13 años la vio operar. Creía que el efecto de la crítica sería mayor si ésta era oblicua. ${ }^{130}$ No obstante, es hora de escuchar lo que Rabasa dijo y escribió. Casi cuando se cumple el centenario de la Constitución de 1917 podemos conocer lo que pensaba de ella en uno de sus aspectos torales. Y la crítica a la Constitución revolucionaria no es menor a la que formuló a la carta de 1857. Escucharla en nuestra circunstancia, en el ocaso del nacionalismo revolucionario y a la luz de las recientes reformas al artículo 27

128 Silva-Herzog, "Emilio Rabasa y el constitucionalismo oficial”, p. 19.

129 Tena, Silueta de don Emilio Rabasa, p. 28.

130 Hale, Emilio Rabasa, p. 90. 
que posibilitaron la reforma energética de 2013 podría ser muy instructivo.

Es cierto que la crítica del jurista a la carta de 1917 cambió con el tiempo. El análisis se hizo más matizado. Reconoció las continuidades y rupturas con la constitución anterior. La obra de Querétaro no había surgido ex nibilo. Rabasa se percató de las tendencias de larga data que la ley fundamental de 1917 había continuado, como la deriva que había sufrido el juicio de amparo en el último tercio del siglo XIX y que Querétaro confirmó y legitimó.

Podemos leer a Rabasa como él mismo se entendía: como un crítico del constitucionalismo mexicano. Tiene razón Jesús Silva-Herzog Márquez cuando señala que la política anticonstitucional, "la práctica que ha logrado levantar al poder por encima del derecho, se ha apoyado en un discurso constitucional”. ${ }^{131}$ A veces la costumbre pesó más que el propio texto constitucional. Sin embargo, hay una continuidad en la crítica constitucional de Emilio Rabasa. El déficit de la carta de 1917 sería un déficit no de gobernabilidad, como antes, sino de libertad. Los revolucionarios podían instituir la inamovilidad de los magistrados en la constitución y de la misma manera podían deshacerla de un plumazo. La Constitución era un atisbo del futuro, un futuro bien aciago para el liberalismo. Había muchas cosas nocivas en la Constitución original y las que estaban bien pronto serían trastocadas. El problema del tercer tercio del siglo xix fue la dictadura producida por una constitución inaplicable; el problema del siglo xx sería el de la simulación constitucional.

131 Silva-Herzog, "Emilio Rabasa”, p. 15. 


\section{SIGLAS Y REFERENCIAS}

CEHMC, AJYL Centro de Estudios de Historia de México Carso, Archivo José Yves Limantour, Ciudad de México.

BLAC, WBP Benson Latin American Collection, William F. Buckley Sr. Papers, E. U.

Arroyo, Israel

"El nuevo diseño de poderes en el constituyente mexicano, 1916-1917: coaliciones parlamentarias y poder judicial”, en Rojas y Deeds (eds.), 2014.

Congreso de la Unión, Cámara de Diputados, L Legislatura

Los derechos del pueblo mexicano. México a través de sus constituciones, México, Porrúa, 1978, t. VII.

Garciadiego, Javier

“¿Dónde quedó el liberalismo?”, en Vázquez (coord.), 1999.

Garner, Paul

British Lions and Mexican Eagles: Business, Politics and Empire in the Career of Weetman Pearson in Mexico, 1889-1919, Palo Alto, Stanford University Press, 2011.

Hale, Charles Adam

Emilio Rabasa and the Survival of Porfirian Liberalism. The Man, his Career, and his Ideas, 1856-1930, Palo Alto, Stanford University Press, 2008.

López Noriega, Saúl y Rodolfo Vázquez (comps.)

Para leer a Rabasa, México, Fontamara, 2011.

Marván Laborde, Ignacio

“Los constituyentes abogados en el Congreso de 1916-1917", México, Centro de Investigación y Docencia Económicas, Documento de Trabajo \# 245, noviembre de 2012. 
Nueva edición del Diario de Debates del Congreso Constituyente de 1916-1917, México, Suprema Corte de Justicia de la Nación, 2006, t. II.

Medina, Hilario

“Emilio Rabasa y la Constitución de 1917”, en Historia Mexicana, x: 2 (38) (oct.-dic. 1960), pp. 177-195.

Rabasa, Emilio O.

"Curso de Derecho Constitucional", en Serra Rojas (comp.), 1969.

El Artículo 14. Estudio Constitucional y el juicio Constitucional, México, Porrúa, 1984.

El derecho de propiedad y la Constitución mexicana de 1917.

La evolución histórica de México, México, Porrúa, 1987.

"La organización de la Suprema Corte y el Juicio de amparo", en Memoria del primer congreso jurídico nacional reunido en la Ciudad de México el 14 de septiembre de 1921 y clausurado el 12 de octubre del mismo año, México, Imp. León Sánchez, 1922.

"Una invención electoral", en Revista Jurídica de la Escuela Libre de Derecho, i: 1-2 (jul.-ago. 1921), en Serra Rojas, 1969.

Reyes Heroles, Jesús

El liberalismo mexicano, México, Fondo de Cultura Económica, 1974, 3 volúmenes.

Rojas, Laura y Susan Deeds (eds.)

México a través de sus revoluciones, México, El Colegio de México, 2014, vol. II.

Serra Rojas, Andrés (comp.)

Antología de Emilio Rabasa, México, Ediciones Oasis, 1969, vols. I y II. 
Silva-Herzog Márquez, Jesús

"Emilio Rabasa y el constitucionalismo oficial”, en López Noriega y Vázquez (comps.), 2011.

Tena Ramírez, Felipe

Silueta de don Emilio Rabasa, México, Cultura, 1935.

VÁzquez, Josefina (coord.)

Recepción y transformación del liberalismo en México. Homenaje al profesor Charles A. Hale, México, El Colegio de México, 1999.

Viesca Lobatón, Francisco

El artículo 27 constitucional (Constitución de 1917). Dictamen de la Comisión nombrada por el Primer Congreso Nacional de Industriales, México, Imprenta I. Escalante, 1917. 